\title{
Strong client orientation, little leverage in nonprofit firms?
}

\author{
Alessandro Fedele • Raffaele Miniaci • \\ Ermanno Tortia
}

Accepted: 10 November 2020 / Published online: 7 January 2021

(C) The Author(s) 2021

\begin{abstract}
Nonprofit firms can be multi-stakeholder organizations, in which employees, clients, volunteers, public institutions, and funders can have formal or informal power to affect corporate strategy. This paper focuses on nonprofit firms' orientation toward clients and investigates its role in shaping capital structure. We first develop a theoretical framework and derive conditions under which the relationship between leverage and client orientation-measured by how much nonprofit firms weigh clients' utility relative to earnings - is either positive or first negative and then positive. We then provide an empirical analysis of social cooperatives in the Italian social care sector and find a negative relationship between leverage and client orientation-proxied by the ratio of voluntary workers to total workforce.
\end{abstract}

Keywords Nonprofit firms · Client orientation · Leverage $\cdot$ Social cooperatives

\footnotetext{
A. Fedele $(\bowtie)$

Faculty of Economics and Management, Free University of Bozen/Bolzano, Piazza Università 1, 39100, Bolzano, Italy e-mail: alessandro.fedele@unibz.it

R. Miniaci

Department of Economics and Management, University of Brescia, Via S.Faustino 74/b, 25122, Brescia, Italy

e-mail: raffaele.miniaci@unibs.it

E. Tortia

Department of Economics and Management, University of

Trento, Via Inama 5, 38100, Trento, Italy

e-mail: ermanno.tortia@unitn.it
}

JEL Classifications G32 - D21 · D22 - L26 · L31

\section{Introduction}

A growing body of literature in economics, finance, and management investigates organizations that pursue more than the goal of profit maximization, such as social enterprises, benefit corporations, nonprofit firms, and socially responsible firms. ${ }^{1}$ These productive organizations have indeed been rising around the globe since several countries developed dedicated legal frameworks (e.g., Borzaga and Fazzi, 2014, and Poledrini and Tortia, 2020). In Europe, notable examples are Belgium (1995 Law on social purpose companies), the UK (2005 Law on community interest companies), and Italy (1991 Law on social cooperatives and 2006 Law on social enterprises). More recently, benefit corporations emerged in the USA. ${ }^{2}$

These productive organizations can be characterized by multi-stakeholder orientation, i.e., they pursue interests not only of financial stakeholders but also of other actors, such as employees, clients, volunteers,

\footnotetext{
${ }^{1}$ Hybrid ventures that conjugate social purposes traditionally attributed to the nonprofit sector, and the economic objectives are usually grouped under the label of social entrepreneurship (Yunus 2007; Wilson and Post 2013).

${ }^{2}$ In 2012, 78 benefit corporations were registered in the USA (Hiller 2013). Currently, 3358 of them are active worldwide (Certified B corporations website, https://bcorporation.net/, last accessed June 17, 2020).
} 
and, more generally, the community. The flourishing of multi-stakeholder organizations has been stimulating debate on the following relevant economic question: how do different stakeholders affect corporate strategy? In (the empirical part of) this paper, we consider a distinctive type of nonprofit multi-stakeholder firms, namely Italian social cooperatives, and a specific stakeholder, namely clients, and we analyze how social cooperatives' orientation toward clients shape their capital structure.

At least three streams of literature in economics and finance, which will be extensively reviewed in Section 2, support the idea that stakeholders other than shareholders influence corporate finance. First, the stakeholder theory of capital structure (Titman 1984) posits that for-profit firms consider preferences of nonfinancial stakeholders when making capital structure decisions, even though not legally required to do so. Second, empirical works study how the corporate social responsibility of for-profit firms impacts on corporate financing (e.g., El Ghoul et al. 2011; Goss and Roberts, 2011). Finally, a number of papers analyze for-profits and nonprofit firms operating in the same industry with the aim of comparing their capital structure choices (e.g., Turner et al. 2015; Fedele and Miniaci 2010). To the best of our knowledge, no paper investigates, both theoretically and empirically, the role played by the intensity of client orientation in shaping the capital structure of nonprofit firms only. The present paper aims to fill this gap.

The core of the paper is divided into two parts. We first develop a theoretical framework, where a representative nonprofit firm is active for two periods, supplies a service to clients, and is barred from distributing profits. This firm maximizes an objective function given by a convex combination between two different values: earnings, which cannot be negative, and clients' utility. The larger the weight given by the nonprofit to the latter value, the higher its (intensity of) orientation toward clients. Being subject to the nondistribution constraint, the firm uses accumulated earnings to finance service provision; if this liquidity is not enough, the firm borrows external funds. We define the firm financial leverage as the ratio of total external debt to total investment in service provision, where the term "total" indicates a discounted sum over the two periods of firm activity. In our stylized model, this total investment coincides with the firm total assets. We solve our framework and find that the relationship between client orientation and leverage is either positive, or first negative and then positive (i.e., U-shaped). The positive relation emerges when client orientation is assumed not to affect the cost of service provision; the reason is that firm earnings shrink when its client orientation augments, causing an increasing need for external debt. Instead, the U-shaped relationship is shown to possibly arise when client orientation impacts on the cost of service provision.

In the second part of the paper, we empirically investigate the link between client orientation and financial leverage. We rely on a longitudinal data set of balance sheets of 6815 Italian social cooperatives (SCs henceforth) supplying residential and nonresidential social and health care services in the 2005-2013 period. $^{3}$ This industry is an ideal setting for our analysis because data are available on both financial leverage and client orientation. In particular, SCs are required to disclose their financial statements, unlike many other private nonprofit institutions. We exploit this feature and proxy the financial leverage of SCs using the ratio of (book values of) total debt to total assets. At the same time, we proxy client orientation using the ratio of voluntary workers to total workforce. The underlying idea is that voluntary workers support SCs with a strong commitment to their clients' well-being. As a consequence, SCs are assumed to be increasingly client-oriented whenever volunteers make up a larger portion of the workforce, everything else equal. On these grounds, we run a multiple regression analysis and observe that the SCs' leverage drops when the ratio of voluntary workers to total workforce increases. More precisely, a one percentage point increase in this ratio is associated with a $0.38 \%$ decrease in leverage. We conclude that the empirical findings capture the decreasing portion of the U-shaped relationship derived in the theoretical framework.

A negative relation between client orientation and leverage is also predicted by the stakeholder theory of capital structure (STCS henceforth). In his

\footnotetext{
${ }^{3}$ As will be discussed in Section 4, Italian SCs are characterized by multi-stakeholder nature, according to which different actors, such as employees, volunteer workers, clients, and suppliers, can directly or indirectly affect decision-making processes. Moreover, Italian SCs are subject to a nonprofit distribution constraint. This means that earnings, if any, must be retained and devoted to financing further production activity, rather than being distributed to financial stakeholders as dividends.
} 
seminal theoretical contribution, Titman (1984) considers the example of for-profit firms selling durable and nondurable goods. Only in the case of durables, firm bankruptcy has costly consequences on clients because of a sharp increase in the goods' maintenance costs. This implies that clients discount ex-ante the bankruptcy risk by reducing their willingness to pay for the product. As a result, firms that sell durables need to reduce leverage to minimize the expected costs of bankruptcy for clients and, this way, maximize profits. In this context, client orientation derives from the durable nature of the product.

Papers comparing for-profits and nonprofit firms in the same industry generally observe lower leverage in the latter. This finding confirms the negative relation between client orientation and leverage as long as it is assumed that nonprofit firms are more likely to have some form of stakeholder orientation than for-profits, everything else equal.

As mentioned, our analysis differs in that the focus is exclusively on nonprofit firms. This is an advantage for two reasons. First, unlike nonprofits, for-profit companies do not operate under a nondistribution constraint. An empirical analysis based on for-profits and nonprofits together would make it difficult to neatly disentangle the effect of client orientation on leverage from that of the nondistribution constraint. Second, our framework considers that SCs, despite their common legal form and nonprofit character, can differ in how they weigh clients' well-being, namely in the intensity of client orientation. This is why our empirical proxy for client orientation is based on the continuous measure given by the voluntary workers to total workers ratio, while a simple dummy variable related to the firms' legal form (for-profit versus nonprofit) is used by papers comparing for-profits and nonprofit firms in the same industry.

Overall, we believe that studying the determinants of nonprofits' capital structure is a relevant research question. From a general perspective, if nonprofit firms are characterized by multi-stakeholder orientation, their financial distress due to high leverage might impose significant costs on various stakeholders. More specifically, consider the nonprofits in our sample. Their clients (e.g., people affected by mental illness, drug addicts, the disabled) and the community as a whole are considered relevant stakeholders, as will be discussed in Section 4. Our paper derives conditions under which nonprofits with increasing leverage are associated with a lower quantity or quality of the service provided. The relevance of the link between financial soundness of nonprofit health care providers and the quality of their services has been highlighted by, e.g., Encinosa and Bernard (2005), Dong (2015), and Akinleye et al. (2019). In turn, several papers show that nonprofits produce better results than other providers in the health and social care sectors when it comes to interactions with families and communities, inclusion of beneficiaries, feelings of engagement, and perceptions of social support, that is, nonprofits increase the social capital of the community (for a review, see Calò et al. 2018). Thus, a reduction in the quantity or quality of the service possibly due to high leverage can impact on the health and wellbeing of clients and the community as a whole.

The remainder of the paper is organized as follows. In Section 2, we discuss the related literature. The theoretical framework is laid out in Section 3. The empirical analysis is developed in Section 4. Section 5 concludes. Mathematical proofs and empirical robustness checks are in the Appendix.

\section{Related literature}

The aim of this section is to discuss in greater detail the three aforementioned streams of literature and other three literatures that are related to this paper.

First, our framework is connected with the theoretical economics literature on organizations that pursue multiple goals. This vast literature adopts the following common way to model the objective function of these types of organization: they are assumed to care about a combination of profits and different stakeholders' welfare. Hediger (2010) models corporate social responsibility (CSR) as a trade-off between companies' financial contribution to shareholders and their contribution to social welfare at large. ${ }^{4}$ Brekke et al. (2012) consider nonprofit firms which care about both profits and consumer welfare, whereas in Fedele and Depedri (2016), nonprofit firms are assumed to maximize consumer welfare subject to a break-even constraint. Herr (2011) focuses on public hospitals, which maximize their own profits plus a fraction of

\footnotetext{
${ }^{4}$ For a survey on corporate social responsibility, see Kitzmüller and Shimshack (2012).
} 
their market share in order to increase patients' welfare. In Szymanska and Jegers (2016), the maximization problem of social enterprises takes into account the objectives of two groups of stakeholders: owners and managers. Our theoretical modelling of the firm objective function is in the spirit of these works.

Second, a stream of literature based on the work by Hansmann $(1980,1996)$ states that nonprofit organizations are effective in minimizing transaction costs due to asymmetric information between supply and demand in the sectors where nonprofits operate. Multi-stakeholder firms are not considered as viable organizational solutions due to inflated costs of decision-making. A more recent stream, instead, points to the multi-stakeholder nature of nonprofit firms as an emerging institutional feature (e.g., Galera and Borzaga 2009; Vidal 2014; Sacchetti and Borzaga 2020). The idea is that a governance structure that involves different stakeholders directly or indirectly affecting corporate decisions can be effective when there is no clear hierarchy among different stakeholder groups in their ability to minimize transaction costs. Since the nonprofit firms considered in our empirical analysis have multi-stakeholder nature, our paper is rooted in this literature.

Third, our research question is strictly related to STCS. As mentioned, Titman (1984) argues that for-profits' capital structure choices result from the intertemporal maximization of profits, which requires that costs borne by stakeholders in the case of bankruptcy are minimized. Empirical tests of STCS proxy stakeholder orientation using various measures of the value of the relationship between firms and stakeholders, such as suppliers, clients, and employees. Kale and Shahrur (2007) consider specific research and development investments and the resulting specificity of the relation between firms and customers (see also Opler and Titman, 1993, 1994). Banerjee, Dasgupta, and Kim Banerjee et al. (2008) focus on the importance of customers and suppliers in terms of percentage of sales and purchases. Other tests have been looking at the specificity of labor relations (e.g., Bae, Kang, and Wang, 2011); skilled workers can prefer less leveraged firms in order to minimize the risk of layoff and the loss of firm-specific human capital.

Fourth, our empirical exercise is related to the literature that studies how the corporate social responsibility of for-profit firms affects corporate finance. Verwijmeren and Derwall (2010) find that firms with leading track records in employee well-being significantly reduce their leverage. The intuition is that lower debt ratios reduce the probability of bankruptcy and, in turn, the loss of income and other nonmonetary benefits incurred by employees. This result is in line with STCS. Goss and Roberts (2011) show that US firms with poor social responsibility bear a significantly higher cost of bank loans than more responsible firms. El Ghoul et al. (2011) find that firms with better CSR scores have access to cheaper equity financing. Lioui and Sharma (2012) highlight a negative correlation between firms' environmental corporate social responsibility and their corporate financial performance. Our contribution departs from both this literature and STCS in that, given our exclusive focus on nonprofits, we provide a radically different definition of and a novel proxy for the stakeholder (client) orientation.

Fifth, our analysis is connected with the literature comparing the capital structure of nonprofit and for-profit entities in the same industry. The seminal contribution by Wedig et al. (1988) deals with proprietary and nonprofit hospitals in the USA and finds no significant differences in capital structures. Wheeler et al. (2000) concentrate on the temporal evolution of leverage in nonprofit and proprietary hospitals in the decade 1986-1997 and do not detect any clear comparative pattern. Fedele and Miniaci (2010) consider nonprofit firms and for-profits operating in the residential care sector in Italy. Results of their longitudinal analysis show that the leverage of nonprofits is $6 \%$ lower than that of for-profits. Trussel (2012) uses cross-sectional data for US proprietary and nonprofit health care organizations in 1995 and in 2005 and finds no difference in the amount of leverage. Turner et al. (2015) use a large panel of investor owned and nonprofit hospitals in the USA. The former are shown to finance $85 \%$ of their assets with debt, while this percentage drops to $52 \%$ for nonprofit hospitals. More recently, Huang, Yang, and Carroll 2018 investigate) US short-term general acute hospitals and find that the leverage in nonprofit hospitals is lower and less volatile. Similarly, Siqueira et al. (2018) provide a comparative longitudinal analysis of Belgian firms and show that young for-profit social enterprises show lower and more stable leverage relative to commercial enterprises. The exclusive focus on nonprofit firms, heterogeneous with respect to client orientation, differentiates our approach from this literature. 
Sixth and last, we briefly discuss the literature on nonprofit capital structure. This stream considers nonprofit firms only. Yet, the role played by stakeholder orientation is not explicitly investigated; the main aim is rather to test the dominant theories of capital structure, trade-off, and pecking order, in the case of nonprofits. Initial studies are performed on nonprofit hospitals in the USA (e.g., Wedig 1990, Wedig, Hassan, and Morrisey 1996, Bacon, 1992). Closer to our analysis are two papers, Bowman (2002) and Calabrese (2011), studying the impact of nonprofit enterprises' restricted endowments on leverage. Restricted endowments are donations of money or property to nonprofits, whose use, destination, and saleability must fulfill donors' preferences. Both papers find that restricted endowments can be negatively related to leverage. Even though stakeholder orientation is not mentioned as a potential determinant of these results, we discuss a possible connection with our analysis. Insofar as restricted endowments represent voluntary contributions of resources to nonprofits, they can take up a role similar to that played by volunteer work in our framework. One might argue that donors tend to give restricted endowments to SCs with a strong commitment to the well-being of intended beneficiaries.

\section{Theoretical setup}

Consider a two-period economy with a nonprofit organization, referred to as firm, that supplies a service to service recipients, referred to as clients. The firm obtains nonnegative earnings, referred to as profits, in every period. Without loss of generality, the firm is assumed to value profits in the first period as much as profits in the second period; in other words, the firm does not discount the future.

Clients Clients derive utility from the service and are characterized by the same per-period utility function. Their preferences over the service are represented by a quasi-linear utility function, $U(q)+m, U^{\prime}(q)>0>$ $U^{\prime \prime}(q)$, where $q$ is the quantity of the service, whose quality level is fixed; $m$ is the amount of a numéraire good. To derive the demand for the service, we make the simplifying assumption that clients maximize utility without caring about the future. In each period, clients choose $q$ and $m$ to maximize utility subject to their budget constraint:

$$
\begin{aligned}
& \max _{q, m} U(q)+m, \\
& \text { s.t. } p q+m \leq I,
\end{aligned}
$$

where $p$ denotes the price per unit of service, $I$ is the clients' income, and the numéraire good price is normalized to one. The following alternative interpretation is compatible with our framework: clients buy only one unit of the service, whose quality level is variable, rather than fixed. In this case, $q$ denotes the quality per unit of service, $p$ the price per unit of quality, and $p q$ indicates the price per unit of service.

In Appendix A.1, we solve problem (1) to obtain the demand for the service, $q(p)$, as a decreasing function of price $p$ and the optimal level of the numéraire good, $m^{*}=I-p q(p)$. Plugging $q(p)$ and $m^{*}$ into the clients' utility function $U(q)+m$ yields the clients' indirect utility function:

$\phi(p)=U[q(p)]+I-p q(p)$.

Applying the envelope theorem to the above function yields $\frac{\partial \phi(p)}{\partial p}<0$, which tells that clients are worseoff when faced with a higher price because they buy a lower quantity/quality of service. This standard result is key to the rest of the analysis.

Firm As mentioned, the firm is active for two periods and does not discount future cash flows. Since clients are characterized by the same indirect utility function $\phi(p)$, without loss of generality, we can restrict our focus on a representative client. In each period $t=\{1,2\}$, the firm objective function is given by the following expression:

$V\left(\alpha, p_{t}\right)=\alpha \phi\left(p_{t}\right)+(1-\alpha) \Pi_{t}$,

where $\alpha \in[0,1]$, referred to as the client orientation parameter, measures how much the firm weighs the indirect utility of its representative client, $\phi\left(p_{t}\right)$, relative to its profits, denoted by $\Pi_{t}$. The higher $\alpha$, the more client-oriented the firm is.

In the first period, the firm profit function is:

$\Pi_{1}=p_{1} q\left(p_{1}\right)-c\left(q\left(p_{1}\right), \alpha\right)$,

where the total cost of service provision, $c(q, \alpha)$, is assumed to be affected by the production level and by the client orientation parameter. We let the first 
derivative $c_{q}$ be strictly positive and the second one $c_{q q}$ be weakly positive. Moreover, to keep the analysis as general as possible, we place no restriction on the sign of the cross derivative $c_{q \alpha}$, which can be positive, zero, or negative. In words, production costs can be linear or convex in $q$ and, for any given $q$, marginal costs $c_{q}$ can increase, be unaffected, or decrease as $\alpha$ rises $^{5}$. Finally, we let $c(0, \alpha)=0$ and $c(q, 0)>0$.

The firm has no cash in the first period; accordingly, the first-period cost $c\left(q\left(p_{1}\right), \alpha\right)$ is financed through a loan ${ }^{6}$. In addition, we suppose that (i) the risk-free interest rate is zero, (ii) lenders are compet- itive, so that they charge no markup on the loan, (iii) the supply of credit is perfectly elastic. These assumptions imply that the amount of the first-period debt is simply $c\left(q\left(p_{1}\right), \alpha\right)$.

In the second period, the firm's cash holdings are given by the first-period profit $\Pi_{1}$. Since nonprofits are barred from distributing profits, the second-period service cost, $c\left(q\left(p_{2}\right), \alpha\right)$, is assumed to be financed through the retained earning $\Pi_{1}$ plus a loan when $\Pi_{1}$ is not sufficient. More precisely, the second-period size of the loan is $\max \left\{0, c\left(q\left(p_{2}\right), \alpha\right)-\Pi_{1}\right\}$ and the firm profit function is:

$$
\Pi_{2}= \begin{cases}p_{2} q\left(p_{2}\right)-c\left(q\left(p_{2}\right), \alpha\right) & \text { if } c\left(q\left(p_{2}\right), \alpha\right) \leq \Pi_{1},(a) \\ p_{2} q\left(p_{2}\right)-\left[\Pi_{1}+\left(c\left(q\left(p_{2}\right), \alpha\right)-\Pi_{1}\right)\right] & \text { if } c\left(q\left(p_{2}\right), \alpha\right)>\Pi_{1} .(b)\end{cases}
$$

Eq. 4a denotes the case where the firm is fully selffinanced, while Eq. $4 \mathrm{~b}$ indicates the scenario where the firm's costs are given by the own funds' opportunity cost, $\Pi_{1}$, plus debt cost, $c q\left(p_{2}\right)-\Pi_{1}$. Note Eq. $4 \mathrm{a}$ is equivalent to Eq. $4 \mathrm{~b}$. In conclusion, we let $\Pi_{t}$ be strictly concave in $p_{t}$.

\subsection{Firm optimal choices}

At the beginning of the first period, the firm solves the following two-period constrained optimization problem:

$$
\begin{gathered}
\max _{p_{t}}\left(\sum_{t=1}^{2} V\left(\alpha, p_{t}\right)=\right) \sum_{t=1}^{2}\left[\alpha \phi\left(p_{t}\right)+(1-\alpha) \Pi_{t}\right], \\
\text { s.t. } \Pi_{t} \geq 0 .
\end{gathered}
$$

The firm chooses the first-period price $p_{1}$ and the second-period price $p_{2}$ to maximize the sum of the two per-period objective functions, subject to the perperiod break-even constraint, $\Pi_{t} \geq 0$. Our analysis is not affected if the firm is assumed to choose the

\footnotetext{
${ }^{5}$ When $q$ denotes the quantity of the service, one might think that a more client-oriented firm incurs higher marginal costs, for instance, because of its willingness to offer a higher quality service. Alternatively, one might believe that a more client-oriented firm bears lower marginal costs because it makes an increasingly rational use of production inputs in order to increase the quantity offered to clients.

${ }^{6}$ One could alternatively assume that the firm is endowed with some cash in the first period. This would complicate calculations without adding new insights.
}

quantity/quality $q$ of the service, rather than the price $p$.

By inspecting (5), one can check that the choice of $p_{1}$ influences only $V\left(\alpha, p_{1}\right)$ but has no effect on $V\left(\alpha, p_{2}\right)$; the same reasoning applies to $p_{2}$, mutatis mutandis. This means that the firm objective function has a stationary structure. At the solution to problem (5), the firm selects the same optimal price in the two periods, $p_{1}^{*}=p_{2}^{*}=p^{*}$, where $p^{*}$ solves the following equality (the proof is in Appendix A.2):

$p^{*}=c_{q}\left(q\left(p^{*}\right), \alpha\right)-\frac{q\left(p^{*}\right)}{q^{\prime}\left(p^{*}\right)} \frac{1-2 \alpha}{1-\alpha}$.

The right hand side (RHS) of Eq. 6 is made of two terms. The first term, $c_{q}\left(q\left(p^{*}\right), \alpha\right)$, is the optimal marginal production cost. The second term, $-\frac{q\left(p^{*}\right)}{q^{\prime}\left(p^{*}\right)} \frac{1-2 \alpha}{1-\alpha}$, describes the (direct) impact of the firm's client orientation on the optimal price. Not surprisingly, this value is decreasing in $\alpha$. If the firm cares increasingly about its representative client, it will set a lower optimal price, therefore enabling the client to be better-off by buying a larger quantity/higher quality of the service. More precisely, $-\frac{q\left(p^{*}\right)}{q^{\prime}\left(p^{*}\right)} \frac{1-2 \alpha}{1-\alpha}$ is nonnegative when $\alpha \leq \frac{1}{2}$ and negative when $\alpha>\frac{1}{2}$. As a result, the optimal price $p^{*}$ is larger than the marginal cost $c_{q}\left(q\left(p^{*}\right), \alpha\right)$ if $\alpha \in\left[0, \frac{1}{2}\right)$, equal to if $\alpha=\frac{1}{2}$, and lower than if $\alpha \in\left(\frac{1}{2}, 1\right]$. Moreover, $\lim _{\alpha \rightarrow 1}\left(-\frac{q\left(p^{*}\right)}{q^{\prime}\left(p^{*}\right)} \frac{1-2 \alpha}{1-\alpha}\right)=-\infty$ : when the firm cares a lot about the client's utility, the price will be set as low as possible. The firm break-even constraint becomes 
therefore active at some $\bar{\alpha}<1$, in which case the optimal price is equal to the average cost $\frac{c\left(q\left(p^{*}\right), \alpha\right)}{q\left(p^{*}\right)}$. Note $\bar{\alpha} \in\left[\frac{1}{2}, 1\right)$ because $c_{q q} \geq 0$ implies that the marginal cost is nonlower than the average cost.

We are interested in studying the effect of $\alpha$ on the optimal quantity/quality of the service, $q\left(p^{*}\right)$ : the proof is in Appendix A.3. First consider the interval $\alpha \in$ $[0, \bar{\alpha}]$. When the marginal cost $c_{q}$ is non-increasing in $\alpha$, i.e., $c_{q \alpha} \leq 0$, the RHS of Eq. 6 decreases with $\alpha$, because its first term is non-increasing in $\alpha$, while the second term, as discussed, is decreasing. As a result, $\alpha$ has a negative impact on $p^{*}$ and, recalling that $q^{\prime}\left(p^{*}\right)<0$, a positive impact on $q\left(p^{*}\right)$. Intuitively, a more client-oriented firm sets a lower price and increases the optimal quantity/quality of the service.

When, instead, the marginal costs are increasing in $\alpha$, i.e., $c_{q \alpha}>0$, the effect of $\alpha$ on $p^{*}$ is ambiguous because the first term of the RHS of Eq. 6 increases with $\alpha$, while the second one decreases. In Appendix A.3, we derive conditions under which $q\left(p^{*}\right)$ is decreasing, or first increasing and then decreasing, or, finally, increasing in $\alpha \in[0, \bar{\alpha}]$. The counterintuitive negative relationship between $q\left(p^{*}\right)$ and $\alpha$ occurs when $c_{q \alpha}$ is relatively high. In this case, a more client-oriented firm sets a higher optimal price because its marginal production costs are significantly larger, with the effect that the client has access to a lower quantity/quality of the service.

Consider now the interval $\alpha \in(\bar{\alpha}, 1]$, in which $p^{*}$ equals the average cost. To investigate the effect of $\alpha$ on $q\left(p^{*}\right)$, it is sufficient to remark that the average cost is unaffected by $\alpha$ when $c_{q \alpha}=0$, decreasing when $c_{q \alpha}<0$, and increasing when $c_{q \alpha}>0$.

We summarize the above findings in the following

Lemma 1 (i) When $c_{q \alpha}<0$, the per-period optimal quantity/quality of the service $q\left(p_{1}^{*}\right)=q\left(p_{2}^{*}\right)=$ $q\left(p^{*}\right)$ is increasing in the client orientation parameter $\alpha \in[0,1]$. (ii) When $c_{q \alpha}=0, q\left(p^{*}\right)$ is increasing in $\alpha \in[0, \bar{\alpha})$ and levels off in $\alpha \in[\bar{\alpha}, 1]$. (iii) When $c_{q \alpha}>0, q\left(p^{*}\right)$ is either increasing, or first decreasing and then increasing, or, finally, decreasing in $\alpha \in$ $[0, \bar{\alpha})$, while $q\left(p^{*}\right)$ is decreasing in $\alpha \in[\bar{\alpha}, 1]$.

To conclude this section, we compute the perperiod optimal profit, $\Pi_{1}^{*}=\Pi_{2}^{*}=\Pi^{*}$, and investigate the relationship between $\Pi^{*}$ and $\alpha$ (the proof is in Appendix A.4). To this aim, we plug $p^{*}$ into Eqs. 3 or 4 and check that: $\Pi^{*}$ is strictly positive when $\alpha \in$ $[0, \bar{\alpha})$ because the optimal price is strictly higher than the average cost; $\Pi^{*}$ is zero when $\alpha \in[\bar{\alpha}, 1]$ because the firm break-even constraint becomes binding. We then restrict our attention to the interval $\alpha \in[0, \bar{\alpha})$ and state the following

Lemma 2 (i) When $c_{q \alpha}<0$, there is an inverted $U$ shaped relationship between the per-period optimal profit $\Pi_{1}^{*}=\Pi_{2}^{*}=\Pi^{*}$ and the client orientation parameter $\alpha \in[0, \bar{\alpha})$. (ii) When $c_{q \alpha} \geq 0, \Pi^{*}$ is decreasing in $\alpha \in[0, \bar{\alpha})$.

A more client-oriented firm is less concerned about profit maximization. This is why it generally earns lower profits. The only exception occurs when $c_{q \alpha}<$ 0 . In this case, $\Pi^{*}$ is initially increasing in $\alpha$ thanks to the decreasing marginal production costs. Yet, $\Pi^{*}$ tends to zero as $\alpha$ gets closer to $\bar{\alpha}$; it must therefore be the case that $\Pi^{*}$ becomes decreasing in $\alpha$ at some threshold value within $(0, \bar{\alpha})$.

\subsection{Optimal leverage}

The last step of our theoretical analysis focuses on the firm's optimal leverage. This value, denoted by $L^{*}$, is defined as the ratio of total debt, $c\left(q\left(p_{1}^{*}\right), \alpha\right)+\max \left\{0, c\left(q\left(p_{2}^{*}\right), \alpha\right)-\Pi_{1}^{*}\right\}$, to total investment, $c\left(q\left(p_{1}^{*}\right), \alpha\right)+c\left(q\left(p_{2}^{*}\right), \alpha\right)$. Recalling that $p_{1}^{*}=p_{2}^{*}=p^{*}, \Pi_{1}^{*}=\Pi_{2}^{*}=\Pi^{*}$, and denoting $c\left(q\left(p_{1}^{*}\right), \alpha\right)=c\left(q\left(p_{2}^{*}\right), \alpha\right)=c^{*}$, the optimal leverage can be simplified as $\frac{c^{*}+\max \left\{0, c^{*}-\Pi^{*}\right\}}{2 c^{*}}$.

More precisely, when $\Pi^{*}=0$, the secondperiod production costs are fully financed by external lenders. In this case, the optimal leverage is $L^{*}=$ $\frac{c^{*}+c^{*}}{2 c^{*}}=1$. By contrast, when $0<\Pi^{*}<c^{*}$, the firm partially resorts to external lenders; the secondperiod debt is $c^{*}-\Pi^{*}$ and the optimal leverage is $L^{*}=\frac{c^{*}+\left(c^{*}-\Pi^{*}\right)}{2 c^{*}}=1-\frac{1}{2} \frac{\Pi^{*}}{c^{*}} \in\left(\frac{1}{2}, 1\right)$. Finally, when $\Pi^{*} \geq c^{*}$, the second-period debt is 0 because the production costs are fully self-financed by the firm. In this case, the optimal leverage is $L^{*}=\frac{c^{*}+0}{2 c^{*}}=\frac{1}{2}$. Summing up:

$$
L^{*}= \begin{cases}1 & \text { when } \Pi^{*}=0, \\ 1-\frac{1}{2} \frac{\Pi^{*}}{c^{*}} \in\left(\frac{1}{2}, 1\right) & \text { when } 0<\Pi^{*}<c^{*}, \\ \frac{1}{2} & \text { when } \Pi^{*} \geq c^{*} .\end{cases}
$$


On the above grounds, we formulate our main research question as follows: What is the effect of client orientation $\alpha \in[0, \bar{\alpha})$ on the optimal leverage $L^{* 7}$ ? Before proceeding, we remark that the mechanism through which client orientation affects leverage is an indirect one. Indeed, the second line of Eq. 7 highlights a negative relationship between the optimal leverage $L^{*}$ and the ratio of optimal profits to optimal total costs, $\frac{\Pi^{*}}{c^{*}}$. In turn, both $\Pi^{*}$ and $c^{*}$ are affected by $\alpha$ via its impact on the optimal quantity/quality of the service provided by the firm, $q\left(p^{*}\right)$.

To answer our research question, we first consider the case where the client orientation has no bearing on marginal costs, that is $c_{q \alpha}=0$. On the one hand, Lemma 1 ensures that the total production costs $c^{*}$ increase with $\alpha$ because of a higher optimal quantity/quality $q\left(p^{*}\right)$ supplied by the firm. On the other hand, Lemma 2 states the per-period optimal profit $\Pi^{*}$ is decreasing in $\alpha$. Overall, it must be that the ratio $\frac{\Pi^{*}}{c^{*}}$ diminishes with $\alpha$ and the optimal leverage $L^{*}=1-\frac{1}{2} \frac{\Pi^{*}}{c^{*}}$ rises because the firm has an increasing need for external funding 8 .

The results are less straightforward if the client orientation has an impact on the marginal costs (i.e., $c_{q \alpha} \neq 0$ ). When $c_{q \alpha}<0$, Lemma 1 implies that the effect of $\alpha$ on $c^{*}$ is ambiguous because, as $\alpha$ rises, the firm produces more/offers higher quality but at a decreasing marginal cost. By contrast, Lemma 2 states that $\Pi^{*}$ is initially increasing and then decreasing in $\alpha$. Based on these premises, in Appendix A.5.2, we show that $L^{*}$ turns out to be either monotonically increasing in $\alpha$, or first strictly decreasing and then monotonically increasing.

Similarly, when $c_{q \alpha}>0$, the impact of $\alpha$ on $c^{*}$ can be ambiguous according to Lemma 1 because, as $\alpha$ rises, the firm can produce less/offer lower quality but at increasing marginal costs. By contrast, Lemma 2 ensures that $\Pi^{*}$ is decreasing in $\alpha$. On these grounds, in Appendix A.5.3, we derive conditions under which $L^{*}$ is either monotonically increasing in $\alpha$, or first strictly decreasing and then monotonically increasing.

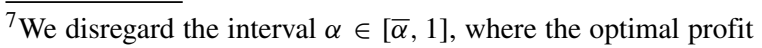
is zero; hence, the leverage is stuck at 1 .

${ }^{8}$ The complete analysis of the case $c_{q \alpha}=0$ is in Appendix A.5.1, where we show that: either (i) $\Pi^{*} \in\left(0, c^{*}\right)$ for any $\alpha \in[0, \bar{\alpha})$, in which case, $L^{*}=1-\frac{1}{2} \frac{\Pi^{*}}{c^{*}}$ is strictly increasing in $\alpha$, as argued in the text; or (ii) $\Pi^{*} \geq c^{*} \Leftrightarrow L^{*}=\frac{1}{2}$, for relatively low values of $\alpha$, and $\Pi^{*}<c^{*}$ for relatively high values; hence, $L^{*}$ turns out to be monotonically increasing in $\alpha$.
}

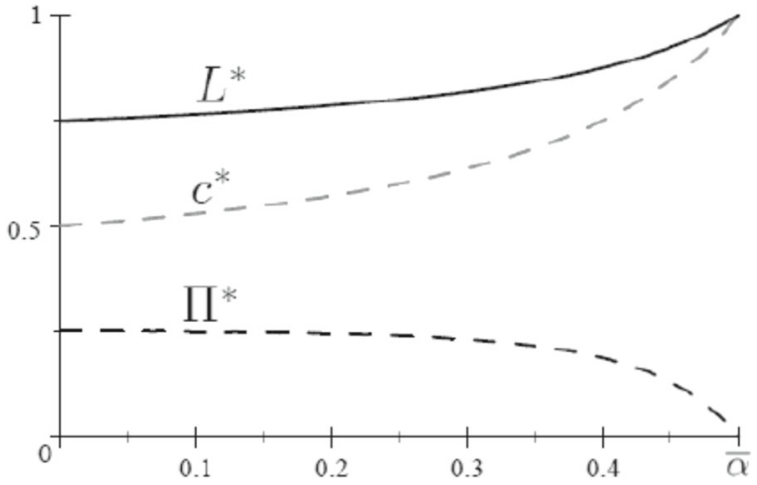

Fig. $1 L^{*} c^{*}$ and $\prod^{*}$ as a function of $\alpha \in[\mathbf{0}, \bar{\alpha}]$ when $c_{q \alpha}=0$

The results of our comparative statics exercise are summarized in the following:

Proposition 1 (i) When $c_{q \alpha}=0$, the firm optimal leverage $L^{*}$ is monotonically increasing in the client orientation parameter $\alpha \in[0, \bar{\alpha})$. (ii) When $c_{q \alpha} \neq 0$, $L^{*}$ can be either monotonically increasing, or first strictly decreasing and then monotonically increasing in $\alpha \in[0, \bar{\alpha})$.

To illustrate the results of Proposition 1 and the indirect mechanism through which $\alpha$ impacts on $L^{*}$, we introduce two figures based on a linear demand $q(p)=2-p$ and linear production costs $\left(c_{q q}=0\right)$.

In Fig. 1, we let the production cost be $c=q$-this is a special case of $c_{q \alpha}=0$-and plot three curves as a function of $\alpha \in[0, \bar{\alpha})$ : the per-period optimal profit $\Pi^{*}$ (lower dashed curve), the per-period optimal cost $c^{*}$ (upper dashed curve), and the optimal leverage $L^{*}$ (solid curve). Since $\Pi^{*}<c^{*}$ for any $\alpha \in[0, \bar{\alpha})$ in this specific illustration, $L^{*}$ is equal to $1-\frac{1}{2} \frac{\Pi^{*}}{c^{*}}$. As predicted by part (i) of Proposition 1 , a more client-oriented firm is associated with a larger leverage. Indeed, $\Pi^{*}$ decreases in $\alpha$, while $c^{*}$ rises, with the effect that the ratio $\frac{\Pi^{*}}{c^{*}}$ decreases and the firm has an increasing need for external funding.

In Fig. 2, we let the production cost $c$ be equal to $(1-\alpha) q$-this is a special case of $c_{q \alpha}<0$ - and plot the same three curves. Again, since $\Pi^{*}<c^{*}$ for any $\alpha \in[0, \bar{\alpha}), L^{*}$ is equal to $1-\frac{1}{2} \frac{\Pi^{*}}{c^{*}}$. As predicted by part (ii) of Proposition 1, the solid curve $L^{*}$ is initially decreasing in $\alpha$ and then increases to 1 . The reason is that at low levels of $\alpha$, the positive impact of client orientation on the optimal profit $\Pi^{*}$, the lower dashed curve, is stronger than that on the optimal costs $c^{*}$, 


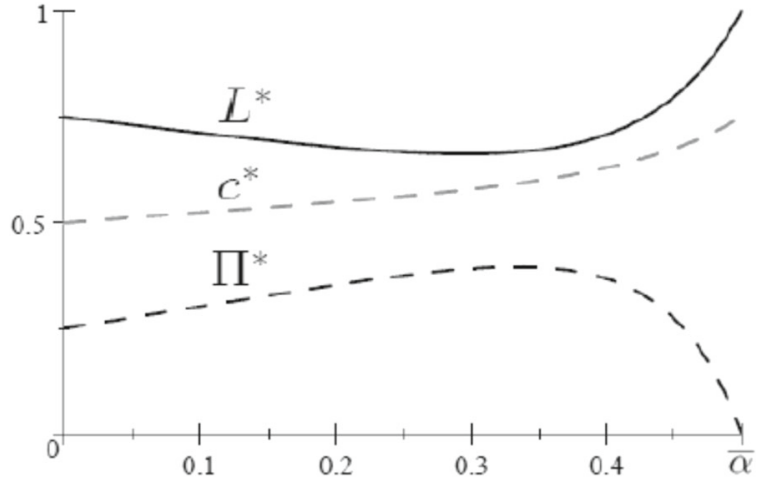

Fig. $2 L^{*} c^{*}$ and $\prod^{*}$ as a function of $\alpha \in[\mathbf{0}, \bar{\alpha}]$ when $c_{q \alpha}<0$

the upper dashed curve; in other words, $\Pi^{*}$ is steeper than $c^{*}$. As a consequence, the ratio $\frac{\Pi^{*}}{c^{*}}$ increases and the firm has a decreasing need for external funding at low levels of $\alpha$. Matching this result on leverage with that on the optimal quantity/quality of the service in Lemma 1 part (i) yields the interesting result an increasing leverage $L^{*}$ is associated with a lower quantity/quality of the service $q\left(p^{*}\right)$, as mentioned in Section 1.

\section{Empirical analysis}

Our theoretical model predicts that the relationship between the optimal leverage of nonprofits and their client orientation can take different forms. An empirical investigation can shed further light by assessing whether and to which extent nonprofits that increasingly weigh their clients' utility rely more or less on external financing. Such analysis should combine information on the capital structure of firms and their client orientation in the corporate decision-making process. As remarked in Section 1, a relevant context in which reliable data on leverage and measures of client orientation are simultaneously available is that of social cooperatives supplying residential care and nonresidential social work activities in Italy. More specifically, we consider SCs whose activities are described by the ATECO 2007 (NACE Rev. 2) codes corresponding to the residential care activities and social work activities without accommodation, that is, SCs operating nursing care activities, residential care activities for mental retardation, mental health and substance abuse, homes for the elderly and disabled, and those providing social assistance without accommodation.
In 2011, the national accounts estimated the value added of residential and nonresidential social service sectors at $0.9 \%$ of the Italian total value added. The 2011 Census of Businesses and Nonprofit Institutions provided by the Italian National Institute of Statistics recorded 43,921 units of service provision, employing about 278,800 people; $82 \%$ of the service units were managed by private nonprofit institutions, representing $79.6 \%$ of the employment in these sectors 9 . The census counted 8343 units managed by nonprofit firms, mainly SCs, employing about 166,000 workers, which amounts to $59.7 \%$ of the private employment in these sectors. In terms of market shares, information was available only for the residential care sector. SCs supplied $18.1 \%$ of the available beds, forprofit enterprises $23.3 \%$ and the remaining quota was split between public institutions $(23.6 \%)$ and other nonprofit institutions (35\%, half of which were ecclesiastical entities).

Regardless of their legal form and nonprofit orientation, the institutions operating in these markets must comply with the same (national and regional) regulations about service standards. Things are instead remarkably different when it comes to disclosure obligations concerning their financial accounts. Only SCs among private nonprofit institutions are required to make their balance sheets publicly available. Other organizations, such as private foundations and associations, are not subject to this obligation. As a consequence, the collection of financial statements provided by the AIDA database (Bureau van Dijk) can be exploited only for $\mathrm{SCs}^{10}$. We find $6815 \mathrm{SCs}$ with valid information in the 2005-2013 period.

A number of reasons point to the multi-stakeholder nature of Italian SCs, despite the fact that workers are the most important internal stakeholder, being highly represented in the membership base and in the boards of directors. First, article 1 of the Law 381/1991 states: "the social cooperatives have the aim of pursuing the general interest of the community in the human promotion and social integration of citizens." Therefore, the community as a whole is a crucial stakeholder of SCs by law. Second, the same Law explicitly provides for the possibility that SCs have an ad hoc category

\footnotetext{
${ }^{9}$ Dati-censimentoindustriaeservizi.istat.it/. ${ }^{10} \mathrm{AIDA}$ is the Italian component of AMADEUS, the European database used in most of the empirical analysis on the capital structure of nonlisted European firms.
} 
of members, namely volunteers, who can play a role in the governance. This means that volunteers are important stakeholders of SCs. Finally, SCs must comply with (additional) social accountability obligations by drawing an annual social report. This document describes in great detail the SCs' contribution to and the relation with different stakeholders, such as paid workers, clients, volunteers, public institutions, financial institutions, and nonfinancial funding institutions.

Among different stakeholders, clients can be considered as relevant stakeholders. Indeed, the SCs in our sample provide essential social and healthcare services to disadvantaged individuals, such as people affected by mental illness, drug addicts, the disabled, and the elderly. Doing so, SCs crucially contribute to the health and wellbeing of clients and, more generally, of their extended families and the community as a whole, in fulfillment of article 1 of the Law 381/1991. On top of that, data from the 2008 Survey on Italian Social Cooperatives (ICSI) show that clients' involvement in activities and projects is considered a strategic objective in most SCs. Borzaga, Depedri, and Tortia (2011) use ICSI data and find that SCs distribute a relevant part of their value added to clients by supplying services for free or below market value. Interestingly, Eq. 6 shows this is the main effect on the optimal service price $p^{*}$ when the value of the client orientation parameter $\alpha$ rises.

Despite the common legal form and nonprofit character, SCs may differ in the weight they give to the well-being of clients. To proxy for client orientation, we rely on voluntary workers by assuming that they tend to operate in SCs with a strong commitment to their clients' well-being. Empirical support to this assumption comes from the 2013 Multipurpose Household Survey of the Italian National Institute of Statistics. ${ }^{11}$ In this survey, volunteers report that the most important determinant of their motivation stems from the commitment toward the mission of the SC and the community they belong to. In particular, about $62.1 \%$ of the people volunteering within organizations declare to be committed because they share the mission of the organization they work at, and $41.7 \%$ to contribute to the community and/or to the environment. Since the community is a crucial stakeholder of SCs according to article 1 of the Law 381/1991 and,

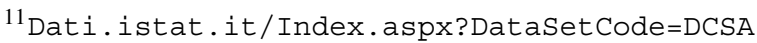
-VOLON
}

in turn, clients and their extended families constitute the core of such community for the SCs contained in our sample, our reading of the above figures is that the main driver of volunteers' motivation is the commitment to deliver a high-quality service to clients. In a similar fashion, Michelutti and Schenkel (2009) show that clients' wellbeing is the main determinant of job satisfaction of volunteers operating in Italian $\mathrm{SCs}^{12}$.

On the above basis, we argue that a SC is increasingly client-oriented whenever volunteers make up a larger portion of the workforce, everything else equal. Data on volunteers are retrieved from the 2011 Census on Businesses and Nonprofit Institutions. Unfortunately, available Census data do not provide the fraction of volunteers for each SC, but only its estimate at the provincial level. Based on these estimates, we compute the ratio of the number of volunteer workers to the total number of workers (i.e., employees, contract workers, and volunteer workers) for the residential and nonresidential service sectors separately in each Italian province (103 clusters). Since data are available only for 2011, this ratio has territorial but not temporal variation.

\subsection{Descriptive statistics}

Table 1 summarizes the main characteristics of our sample of 6815 SCs. We consider financial statements that satisfy a set of minimal consistency check ${ }^{13}$. The average number of observations per SC is 5.7 in the $2005-2013$ period. About $20 \%$ of the 38,758 observations pertain to SCs operating in the residential sector, and $24 \%$ to SCs that have been operating for at most 5 years (that we label "Start-up"). The SCs are quite heterogeneous in size- the value of total assets ranges from 5800 euro to more than 11.4 million euro and the median value is 244,551 euro-and in the incidence

\footnotetext{
${ }^{12}$ The 2013 survey also reports that only $5.5 \%$ of the volunteers aim to improve their professional experience and/or to have better chance of employment. Marino and Schenkel (2017) find similar evidence using data on volunteers in Europe, North, and South America. These findings seem to exlcude that volunteers are prospective workers.

${ }^{13}$ In particular, we exclude financial statements with negative total assets, turnover, equity, and total labor cost. We also drop SCs with implausible commencement date and financial statements that are published after the initiation of a bankruptcy proceeding. We finally remove observations with leverage falling outside the $0-3$ range $(0.6 \%$ of the available set) and those whose labor costs/total production value ratio is above $1(2.1 \%$ of the available set).
} 
Table 1 Descriptive statistics

\begin{tabular}{|c|c|c|c|c|c|}
\hline & \multicolumn{5}{|c|}{ Percentile } \\
\hline & Mean & 1 & 50 & 99 & Std. deviation \\
\hline \multicolumn{6}{|l|}{ Cooperative-specific variables } \\
\hline Leverage & 0.6051 & 0.0637 & 0.5936 & 1.6476 & 0.3163 \\
\hline Total assets (1000 euro, 2010 prices) & 958.83 & 5.82 & 244.55 & 11413.34 & 3457.2 \\
\hline Tangible assets/total assets & 0.1403 & 0 & 0.0613 & 0.8197 & 0.1887 \\
\hline ROA & 0.0549 & -0.7076 & 0.0602 & 0.5771 & 0.2059 \\
\hline Labor costs/total production value & 0.5797 & 0.0119 & 0.6178 & 0.9584 & 0.2275 \\
\hline Operating grants/total production value & 0.0310 & 0 & 0 & 0.5362 & 0.0984 \\
\hline Residential services $(0 / 1)$ & 0.2036 & 0 & 0 & 1 & 0.4027 \\
\hline Start up $(0 / 1)$ & 0.2401 & 0 & 0 & 1 & 0.4272 \\
\hline \multicolumn{6}{|l|}{ Provincial-specific variables } \\
\hline Voluntary workers/total workforce & 0.1001 & 0.0045 & 0.0851 & 0.2738 & 0.0670 \\
\hline New nonperforming loans/performing loans & 2.5520 & 0.4399 & 2.2739 & 7.9614 & 1.5991 \\
\hline Net flow of new companies/active companies & 0.5088 & -3.2680 & 0.5287 & 2.9396 & 1.2307 \\
\hline Population over 55/total population & 0.3278 & 0.2502 & 0.3246 & 0.4095 & 0.0336 \\
\hline Population (1000) & 1032.47 & 159.72 & 629.79 & 3995.25 & 1026.66 \\
\hline Added value per capita(1000 euro, 2010 prices) & 23.92 & 12.92 & 23.78 & 46.71 & 7.78 \\
\hline Employment rate (percentage) & 56.91 & 36.72 & 61.75 & 71.02 & 10.18 \\
\hline Number of observations per SC & 5.7 & 1 & 6 & 9 & 2.87 \\
\hline
\end{tabular}

of labor cost on the total production value-this ratio varies between 1 and $96 \%$, with a mean of $58 \%{ }^{14}$. Some SCs have a negligible ratio of tangible assets to total assets, whereas others can put up a relatively high amount of tangible assets as collateral; the average value is $14 \%$. Operating grants are typically funds from public and private nonfinancial institutions; the ratio of operating grants to total production value has a mean of $3.1 \%$, a median of zero, and peaks above $53 \%$, making apparent that most SCs, despite their nonprofit nature, do not rely on the support of public authorities, private foundations, and donors for their financial sustainability. The Return on Assets (ROA) index computed as the ratio of earnings before interest, taxes, depreciation, and amortization (EBITDA) to total assets is equal to $5.5 \%$ on average, with extreme values below $-70 \%$ and above $57 \%$. Negative values

\footnotetext{
${ }^{14}$ The ratio of labor cost to total production value captures not only the differences in the labor intensity of the SCs' activities but also any effect of the voluntary work on labor costs. This control variable, along with article 2 of the Law 381/91 that prevents situations where volunteers act as a replacement for professional operators, should ensure that an increasing value of our proxy for client orientation does not, instead, capture lower labor costs.
}

of earnings are not surprising if we consider that the 2005-2013 period includes the Great Recession that began in 2008 and had long-lasting effects in Italy. Finally, we proxy the financial leverage of SCs by relying on the book leverage ratio, that is, the ratio of total debt to total assets (at book value). This measure of capital structure is often used in the empirical corporate finance literature (e.g., Bake and Wurgler 2002; de Jong, Verbeek, and Verwijmeren, 2011, and Halling, Yu, and Zechner, 2016) ${ }^{15}$. The mean value of this ratio is $60 \%$; the sample, however, includes SCs with a negligible leverage level as well as SCs whose leverage is larger than one.

As mentioned, our voluntary workers/total workforce ratio that proxies SCs' client orientation is computed in 2011, per sector, and in the province where each SC is located. On average, this ratio is equal to $10 \%$, with a significant variation across provinces.

\footnotetext{
${ }^{15}$ The use of book values rather than market values is because SCs are not listed companies. The use of total debt rather than financial debt is because publicly available balance sheets generally do not provide sufficient information to distinguish between long-term and short-term debt, or between bank and commercial debt.
} 
Clearly, this is not the only dimension for which differences arise among geographic areas. Provinces also differ with respect to (i) the size and productivity of the local economies, that is related to the population, the per-capita added value and the employment rate; (ii) the riskiness of local credit markets, which is measured by the new nonperforming loans/performing loans ratio; (ii) the business cycle, which is described by the net flow of new companies/active companies ratio; (iv) the pool of potential volunteers. As for point (iv), the 2013 Multipurpose Household Survey shows that people aged 55 or more supply $48 \%$ of total unpaid working hours in Italian voluntary organizations, despite the fact that they account for only $22 \%$ of the total number of volunteers. We therefore consider the ratio population over $55 /$ total population as a proxy for the potential supply of unpaid working hours in the social cooperative sector at the provincial level.

\subsection{Regression analysis}

We run a multiple regression analysis to investigate the relationship between SCs' client orientation and their use of debt, all other things kept equal. In particular, we consider a log-linear specification of the regression equation, that is, we assume the conditional mean of the logarithm of leverage to be a linear function of the proxy for client orientation. Doing so, the parameter associated with this proxy, $\delta$ in Eq. 8 below, can be interpreted in terms of semi-elasticity because it informs about the percentage change in leverage following a one percentage point variation in the voluntary workers/total workers ratio.

We postulate the following model for the conditional mean of the $(\log )$ leverage,

$\log L_{i p t}=X_{i p t}^{\prime} \beta_{\tau}+P_{p t}^{\prime} \gamma+Z_{t}^{\prime} \pi+V_{p} \delta+v_{i p}+e_{i p t}$,

where $\log L_{i p t}$ is the $\log$ of the leverage of SC $i$ operating in province $p$ at time $t ; X_{i p t}$ are the coop-specific variables and $P_{p t}$ the provincial-specific variables whose statistics are displayed in Table $2 ; Z_{t}$ is a set of time dummies that controls for national business cycle effects; finally, $V_{p}$ is the proxy for SCs' client orientation.

The set of covariates $X_{i p t}$ is consistent with the corporate finance literature (for a survey, see Parsons and Titman, 2008). In particular, these covariates describe determinants of both the target leverage and the deviations from the target, referred to as the first and second ingredients in the empirical analysis of leverage by Parsons and Titman (2008). The ratio of operating grants to total production value captures some of the peculiarities of the nonprofit sector, as it is a potential key determinant of nonprofit enterprises' capital

Table 2 OLS estimates of Eq. 8. Specification includes also time $\left(Z_{t}\right)$ dummies. Standard errors robust to heteroskedasticity and clustering at provincial level (103 clusters). Number of obs $=38,758 ; R^{2}=0.1072 ; R_{\text {adjusted }}^{2}=0.1095$

\begin{tabular}{|c|c|c|c|c|c|c|}
\hline & Coef. & Std. Err. & $t$ & $p$ value & $95 \%$ Conf. & Interval \\
\hline Voluntary workers/total workforce & -0.4188 & 0.1600 & -2.6200 & 0.0100 & -0.7361 & -0.1014 \\
\hline $\log$ (total assets) & 0.0006 & 0.0070 & 0.0800 & 0.9350 & -0.0133 & 0.0144 \\
\hline Tangible assets/total assets & -0.0007 & 0.0469 & -0.0100 & 0.9890 & -0.0937 & 0.0924 \\
\hline ROA & -0.7194 & 0.0229 & -31.3500 & 0.0000 & -0.7650 & -0.6739 \\
\hline Labor costs/total production value & -0.2532 & 0.0374 & -6.7600 & 0.0000 & -0.3274 & -0.1790 \\
\hline Operating grants/total production value & -0.3150 & 0.0940 & -3.3500 & 0.0010 & -0.5014 & -0.1286 \\
\hline Residential services & -0.0725 & 0.0198 & -3.6700 & 0.0000 & -0.1117 & -0.0333 \\
\hline Start up & 0.2851 & 0.0187 & 15.2100 & 0.0000 & 0.2479 & 0.3222 \\
\hline New nonperforming loans/performing loans & 0.0094 & 0.0051 & 1.8400 & 0.0690 & -0.0007 & 0.0195 \\
\hline Net flow of new companies/active companies & 0.0084 & 0.0046 & 1.8400 & 0.0690 & -0.0007 & 0.0175 \\
\hline Population over 55/total population & 1.4199 & 0.4504 & 3.1500 & 0.0020 & 0.5266 & 2.3132 \\
\hline $\log$ (population) & 0.0490 & 0.0177 & 2.7700 & 0.0070 & 0.0140 & 0.0841 \\
\hline Added value per capita & 0.0364 & 2.2462 & 0.0200 & 0.9870 & -4.4189 & 4.4917 \\
\hline Employment rate & -0.0052 & 0.0019 & -2.7700 & 0.0070 & -0.0089 & -0.0015 \\
\hline Constant & -1.3256 & 0.2930 & -4.5200 & 0.0000 & -1.9068 & -0.7444 \\
\hline
\end{tabular}


structure (e.g., Bowman, 2002). Variables in $P_{p t}$ aim to control for the presence of factors that vary at the provincial level and may affect the financing of SCs; if these variables are correlated with our proxy $V_{p}$, their omission may potentially distort our estimates of the parameter $\delta$. After dropping few influential observations (less than $0.2 \%$ of the original observations), we estimate the parameters of Eq. 8 using OLS with standard errors clustered at the provincial level. The OLS estimates are therefore consistent under the assumption that all covariates are correlated neither with the time invariant component $v_{i p}$ nor with the idiosyncratic component $e_{i p t}$ of the regression error.

Before commenting on the results, we discuss a number of potential issues and the ways we deal with them.

First, the theoretical measure of client orientationparameter $\alpha$-is an exogenous determinant of the firm leverage. The empirical proxy for $\alpha$ (i.e., the ratio of volunteer workers to the total number of workers) might instead give rise to the following reverse causality problem. SCs willing to keep its leverage low may recruit more volunteers in order to reduce operating costs and thus the need for external financing. We believe this potential issue does not arise here. The reason is that our proxy is computed at the provincial level in 2011 and not at the firm level in the 20052013 period. Even if some SCs were able to alter their proportion of volunteer workers, the provincial ratio would hardly be affected.

Second, the static nature of Eq. 8 and the inclusion of the SCs' financial variables $X_{i p t}$ are potential sources of misspecification. Indeed, the degree of indebtedness of a company may have some degree of persistence that Eq. 8 does not account for (e.g., Devereux, Maffini, and Xing, 2019). Moreover, the variables included in $X_{i p t}$ could be correlated with the SCspecific time-invariant component of the regression error, $v_{i p}$, and we cannot exclude that some reverse causality is present. For instance, it is likely that the level of indebtedness has an impact on the amount of assets the SCs can afford. To account for these aspects, in Appendix B.1, we consider a dynamic version of our model using a parsimonious Arellano-Bover-style GMM estimator (Arellano and Bover 1995) in which $P_{p t}, Z_{t}$, and $V_{p}$ are the instrumental variables used for the orthogonality conditions of the equation in levels, whereas the second and third lags of $\log L_{i p t}$ and $X_{i p t}$ are used as instruments for the first-difference orthogonality conditions. Results turn out to be qualitatively equivalent to those presented here.

A third potential threat to the reliability of the estimates comes from unobserved heterogeneity. In Appendix B.2, we assess to what extent our results are robust to the presence of unobserved heterogeneity by following Oster (2019). We show that the estimated relation between our proxy for client orientation and the SCs' leverage maintains its statistical relevance also in presence of a significant amount of unobserved heterogeneity.

Finally, there is a potential concern related to the heterogeneity of residential and nonresidential sectors. Our sample includes 1423 SCs operating in the residential service sector, and 5390 supplying nonresidential services. The two types of SC differ in some fundamental domains. (i) SCs are larger in the residential sector, where the sample median value of assets is 328,741 euro; this value drops to 224,119 euro in the nonresidential sector. (ii) Residential SCs are endowed with more tangibles - on average, $17.93 \%$ vs $13.03 \%$ of the total assets - and higher ROA- $6.76 \%$ vs $5.16 \%$ on average. (iii) The proportion of voluntary workers is similar in the two groups (about 10\% on average); yet, the relationship between client orientation and leverage might differ across sectors given their different productive, organizational, and financial structures. To address these potential issues, in Appendix B.3, we re-estimate our model by separately considering the two sectors. Results turn out to be in line with those derived in this section.

Table 2 shows the OLS estimates of the parameters of main interest in Eq. 8. First note that both total assets and the fraction of tangible assets do not seem to be major determinants of leverage in our sample. Instead, the ROA has a negative and significant impact on leverage, in line with the empirical literature supporting the pecking order theory of capital structure (e.g., Myers and Majluf, 1984), and the idea that nonprofits, being barred from distributing profits, invest them in the production activity. The SCs with more labor intensive activities are less prone to resort to debt. A similar negative relation arises between leverage and the amount of operating grants, which are indeed likely to reduce the need for external funding (in line with the pecking order theory and the evidence provided by Bowman, 2002, and Calabrese, 2011). The leverage of SCs in the residential service sector is $7.25 \%$ lower than the leverage of those active in the nonresidential sector, whereas the leverage of start-ups 
is $28.5 \%$ higher than that of SCs that have been operating for more than 5 years. The SCs have a higher leverage if they operate in provinces with larger and older population and with lower employment rates. Both the new nonperforming loans/performing loans and the net flow of new companies/active companies ratios are associated with higher level of leverage of the SCs.

As for our main variable of interest, that is the proxy for SCs' client orientation, we observe that leverage decreases when the ratio of voluntary workers to total workforce increases. More precisely, a one percentage point increase in this ratio is associated with a $0.42 \%$ decrease in the leverage of the SC. Equivalently, a standard deviation change in client orientation reduces leverage by $2.8 \%$. We can conclude that, after controlling for possible concurrent determinants of the indebtedness level, the (proxy for) client orientation is negatively and significantly connected with the leverage of SCs. ${ }^{16}$

Our theoretical model can help shedding light on this empirical finding. To this aim, we rewrite the theoretical formula for the optimal leverage, i.e., the second line of Eq. 7:

$L^{*}=1-\frac{1}{2} \frac{\Pi^{*}(\alpha)}{c^{*}(\alpha)}$.

Eq. 9 suggests that a negative relationship between client orientation $\alpha$ and leverage $L^{*}$ can be interpreted as follows: parameter $\alpha$ positively impacts on the ratio of profit to total cost, $\frac{\Pi^{*}(\alpha)}{c^{*}(\alpha)}$, which in turn decreases the need for external funding. This is the mechanism described in Section 3.2 and illustrated in Fig. 2. Now suppose that, using the available data on SCs' financial statements, we are able to construct an empirical measure of the RHS of Eq. 9. If this object turns out to be decreasing in our proxy for client orientation, we can reasonably argue that our theoretical mechanism is compatible with the empirical findings.

We construct our empirical measure as follows. For each SC, we compute the mean of 1 EBITDA

\footnotetext{
${ }^{16}$ As a robustness check, one could consider a firm-level proxy for client orientation, for instance using the amount of donations received by each SC. Unfortunately, this information cannot be retrieved from the AIDA database; only operating grants can be identified, which may include donations from clients. Interestingly, if we interpreted the ratio of operating grants to total production value as a proxy for client orientation, we would confirm the result that more client-oriented SCs have lower leverage.
}

regress it on the voluntary workers/total workers ratio using a kernel-weighted local polynomial regression. The resulting curve, along with the $95 \%$ confidence band, is the lower one plotted in Fig. 3 and turns out to decrease with the client orientation proxy up to the 90th percentile. We therefore cannot exclude that the empirical negative relationship between client orientation and leverage is the result of a positive link between leverage and the ratio $\frac{\text { EBITDA }}{\text { Total production costs }}$, as suggested by our theory.

Figure 3 also provides the same exercise for (the log of) the total debt/total asset ratio, our empirical proxy for the SCs' leverage. The outcome is the upper curve, which turns out to be downward-sloping as well. This means that, at a descriptive level, higher client orientation is associated with less leverage, be it defined by the total debt/total asset ratio or by the RHS of Eq. 9 .

\section{Conclusion}

Our analysis contributes to the lively debate on how different stakeholders affect the corporate strategy of multi-stakeholder productive organizations. To this aim, we investigated how the capital structure of nonprofit firms, whose objective function is a convex combination between earnings and clients' utility, is affected by the weight put on clients.

We built a partial equilibrium model to show that if such weight is above a given threshold, firms expand their production (or quality) up to the limit imposed by the break-even constraint and the leverage is maximum. Below this threshold, the relationship between leverage and client orientation is positive, provided that client orientation does not affect marginal costs. When, instead, client orientation does affect marginal costs, the relationship is either positive or first negative and then positive.

We then developed an empirical analysis of social cooperatives in the Italian social care sector and found a negative relationship between leverage and client orientation, proxied by the ratio of voluntary workers to total workforce. This evidence shows it is the decreasing portion of the theoretical relationship between client orientation and leverage that has empirical relevance. Robustness checks proved that the empirical results are not affected by changes in the estimation methods, unobserved heterogeneity, and estimation samples. 
Fig. 3 Relationship between SC's leverage and the volunteers/total workers ratio

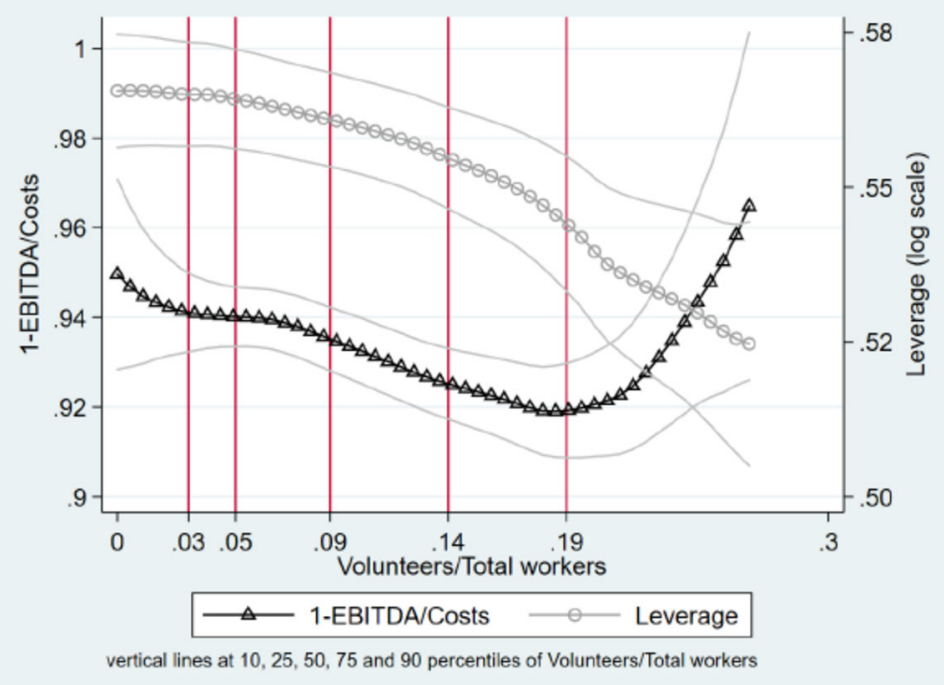

We mention two possible directions for future research. From a theoretical point of view, it might be interesting to consider competing nonprofit firms operating in the same market, rather than a single representative organization. From an empirical point of view, the analysis could be enriched by data sources that provide direct information on how different stakeholder groups determine corporate strategies.

Acknowledgments We thank two anonymous reviewers, Steven Stillman, and the seminar audience at AISRE (Bolzano, September 2018), ERSA (Cork, August 2018), IAFEP (Lubiana, July 2018), IMAEF (Corfu, June 2018), 2nd Bozen/Bolzano Internal Workshop on Economics and Econometrics (Bolzano, June 2018), University of Udine (May 2018), University of Trento (May 2018) LUMSA University (Roma, December 2016), the International Conference on Applied Research in Economics (Essex, September 2016), the XXIV International Rome Conference on Money, Banking and Finance (Roma, December 2015), and Kore University of Enna (May 2015) for constructive comments. Alessandro Fedele gratefully acknowledges financial support from the Free University of Bolzano (research grant WW2816).

Funding Open access funding provided by Libera Università di Bolzano within the CRUI-CARE Agreement.

Open Access This article is licensed under a Creative Commons Attribution 4.0 International License, which permits use, sharing, adaptation, distribution and reproduction in any medium or format, as long as you give appropriate credit to the original author(s) and the source, provide a link to the Creative Commons licence, and indicate if changes were made. The images or other third party material in this article are included in the article's Creative Commons licence, unless indicated otherwise in a credit line to the material. If material is not included in the article's Creative Commons licence and your intended use is not permitted by statutory regulation or exceeds the permitted use, you will need to obtain permission directly from the copyright holder. To view a copy of this licence, visit http:// creativecommonshorg/licenses/by/4.0/.

\section{Appendix A: Theoretical setup: proofs}

\section{A.1 Client problem}

The Lagrangean of problem (1) is $U(q)+m-$ $\lambda(p q+m-I)$; the system of first-order conditions (FOCs) is:

$$
\left\{\begin{array}{l}
\frac{\partial}{\partial q}=0 \Rightarrow U^{\prime}(q)-\lambda p=0, \\
\frac{\partial}{\partial m}=0 \Rightarrow 1-\lambda=0, \\
\frac{\partial}{\partial \lambda}=0 \Rightarrow p q+m-I=0 .
\end{array}\right.
$$

The third equality can be rewritten as $m=I-p q$. Plugging the second equality into the first one yields $U^{\prime}(q)-p=0$; the solution to this equation is denoted by $q(p)$. Applying the implicit function theorem to $U^{\prime}(q)-p=0$ yields:

$$
\frac{\partial q(p)}{\partial p}=\frac{1}{U^{\prime \prime}(q)}<0 .
$$

\section{A.2 Optimal price $p^{*}$}

We solve problem (5) as an unconstrained maximization problem and investigate ex-post the role played by the break-even constraints $\Pi_{t} \geq 0$. The objective 
function is stationary; this enables us to anticipate that $p_{1}=p_{2}=p$ at the optimum; we thus differentiate the per-period objective function:

$$
\begin{aligned}
V(\alpha, q(p))= & \alpha\{U[q(p)]+I-p q(p)\} \\
& +(1-\alpha)[p q(p)-c(\alpha, q(p))]
\end{aligned}
$$

wrt $p$. The FOC is:

$$
\begin{aligned}
\frac{\partial V(\alpha, p)}{\partial p}=0 & \Rightarrow \alpha[-q(p)]+(1-\alpha)[q(p) \\
& \left.+p q^{\prime}(p)-c_{q}(\alpha, q(p)) q^{\prime}(p)\right]=0 .
\end{aligned}
$$

Rearranging (11) yields (6).

\section{A.3 Proof of Lemma 1}

To study the sign of $\frac{\partial q\left(p^{*}\right)}{\partial \alpha}=\frac{\partial q\left(p^{*}\right)}{\partial p^{*}} \frac{\partial p^{*}}{\partial \alpha}$ in $\alpha \in[0, \bar{\alpha}]$, we recall that $\operatorname{sign} \frac{\partial q\left(p^{*}\right)}{\partial \alpha}=-\operatorname{sign} \frac{\partial p^{*}}{\partial \alpha}$ given (10). We hence focus on $\frac{\partial p^{*}}{\partial \alpha}$ and invoke the implicit function theorem, according to which $\frac{\partial p^{*}}{\partial \alpha}=-\left(\frac{\partial \text { LHS of (11) }}{\partial \alpha}\right) /\left(\frac{\partial \text { LHS of (11) }}{\partial p^{*}}\right)$, LHS standing for left hand side. By definition of maximum, the sign of $\frac{\partial \text { LHS of (11) }}{\partial p^{*}}$ is negative, hence $\operatorname{sign} \frac{\partial p^{*}}{\partial \alpha}=$ $\operatorname{sign} \frac{\partial \text { LHS of }(11)}{\partial \alpha}$, where:

$\frac{\partial \text { LHS of }(11)}{\partial \alpha}=-2 q\left(p^{*}\right)-q^{\prime}\left(p^{*}\right)\left[p^{*}-c_{q}+(1-\alpha) c_{q \alpha}\right]$.

This expression is negative if:

$p^{*}-c_{q}<-\frac{2 q\left(p^{*}\right)}{q^{\prime}\left(p^{*}\right)}-(1-\alpha) c_{q \alpha}$.

Plugging Eq. 6 into Eq. 12 and rearranging yields:

$c_{q \alpha}<-\frac{q\left(p^{*}\right)}{q^{\prime}\left(p^{*}\right)} \frac{1}{(1-\alpha)^{2}}$.

The RHS of Eq. 13 is positive; hence, Eq. 13 is fulfilled when $c_{q \alpha} \leq 0$, in which case $\frac{\partial p^{*}}{\partial \alpha}<0$ for any $\alpha \in$ $[0, \bar{\alpha}]$. When instead $c_{q \alpha}>0$, we rearrange (13) as:

$\alpha \geq 1-\left(-\frac{q\left(p^{*}\right)}{q^{\prime}\left(p^{*}\right)} \frac{1}{c_{q \alpha}}\right)^{\frac{1}{2}}$.

We consider two alternative scenarios.

(i) If $c_{q \alpha}<-\frac{q\left(p^{*}\right)}{q^{\prime}\left(p^{*}\right)}$, the RHS of Eq. 14 is negative; hence, (14) is fulfilled and $\frac{\partial p^{*}}{\partial \alpha}<0$.

(ii) If $c_{q \alpha}>-\frac{q\left(p^{*}\right)}{q^{\prime}\left(p^{*}\right)}$, the RHS of Eq. 14 is positive. In this case, we assume that at most one value of $\alpha \in[0, \bar{\alpha}]$, denoted by $\alpha^{\circ}$, solves Eq. 14 with equality. Since Eq. 14 is not fulfilled at $\alpha=0$, it follows that: Eq. 14 is never fulfilled when $\alpha^{\circ}>$ $\bar{\alpha}$ because $\alpha \leq \bar{\alpha}<\alpha^{\circ}$; hence, $p^{*}$ is increasing for any $\alpha \in[0, \bar{\alpha}]$; when $(0<) \alpha^{\circ}<\bar{\alpha}, p^{*}$ is increasing in $\alpha \in\left[0, \alpha^{\circ}\right)$ and $\alpha \in[\bar{\alpha}, 1]$, and decreasing in $\alpha \in\left[a^{\circ}, \bar{\alpha}\right)$.

\section{A.4 Proof of Lemma 2}

The derivative of the optimal profit $\Pi^{*}$ with respect $\alpha \in[0, \bar{\alpha})$ is:

$\frac{\partial \Pi^{*}}{\partial \alpha}=\frac{\partial p^{*}}{\partial \alpha} q\left(p^{*}\right)+p^{*} q^{\prime}\left(p^{*}\right) \frac{\partial p^{*}}{\partial \alpha}-c_{\alpha}-c_{q} q^{\prime}\left(p^{*}\right) \frac{\partial p^{*}}{\partial \alpha}$.

This value is nonnegative if:

$\left(p^{*}-c_{q}\right) q^{\prime}\left(p^{*}\right) \frac{\partial p^{*}}{\partial \alpha}+\frac{\partial p^{*}}{\partial \alpha} q\left(p^{*}\right) \geq c_{\alpha}$.

Plugging Eq. 6 into the LHS yields:

$$
\begin{aligned}
& \left(-\frac{q\left(p^{*}\right)}{q^{\prime}\left(p^{*}\right)} \frac{1-2 \alpha}{1-\alpha}\right) q^{\prime}\left(p^{*}\right) \frac{\partial p^{*}}{\partial \alpha}+\frac{\partial p^{*}}{\partial \alpha} q\left(p^{*}\right) \\
& \geq c_{\alpha} \Leftrightarrow \frac{\partial p^{*}}{\partial \alpha} q\left(p^{*}\right) \frac{\alpha}{1-\alpha} \geq c_{\alpha} .
\end{aligned}
$$

Suppose first $\frac{\partial p^{*}}{\partial \alpha}<0$ : we get:

$\frac{\alpha}{1-\alpha} \leq \frac{c_{\alpha}}{\frac{\partial p^{*}}{\partial \alpha} q\left(p^{*}\right)}$.

The LHS is weakly positive and increasing in $\alpha \in$ $[0, \bar{\alpha})$, while the RHS is weakly negative if $c_{\alpha} \geq 0$ and positive if $c_{\alpha}<0$. Our assumptions on the production cost function imply that $\operatorname{sign} c_{\alpha}=\operatorname{sign} c_{q \alpha}$. It follows that (i) (15) is never fulfilled when $c_{q \alpha} \geq 0$ because the RHS of Eq. 15 is negative, in which case $\Pi^{*}$ is decreasing in $\alpha$; (ii) when $c_{q \alpha}<0$, both sides of Eq. 15 are strictly positive; hence, Eq. 15 is fulfilled in a right neighborhood of $\alpha=0$ where $\frac{\alpha}{1-\alpha}$ tends to $0 ; \Pi^{*}$ thus increases with $\alpha$ in this right neighborhood. Assuming $\Pi^{*}>0$ at $\alpha=0$ and having proved that $\Pi^{*}=0$ at $\alpha=\bar{\alpha}$, it must be the case that $\Pi^{*}$ is initially increasing, but then decreasing in $\alpha \in[0, \bar{\alpha}]$.

Suppose now $\frac{\partial p^{*}}{\partial \alpha}>0 ; \frac{\partial \Pi^{*}}{\partial \alpha}$ is nonnegative if:

$\frac{\alpha}{1-\alpha} \geq \frac{c_{\alpha}}{\frac{\partial p^{*}}{\partial \alpha} q\left(p^{*}\right)}$.

Recall from Lemma 1 that $\frac{\partial p^{*}}{\partial \alpha}$ can be positive only when $c_{q \alpha}>-\frac{q\left(p^{*}\right)}{q^{\prime}\left(p^{*}\right)}(>0)$, which implies that $c_{\alpha}>0$ and, in turn, that the RHS of Eq. 16 is positive. This means that Eq. 16 is not fulfilled in a right neighborhood of $\alpha=0$. It follows that $\Pi^{*}$ is initially decreasing in $\alpha$. Assuming $\Pi^{*}>0$ at $\alpha=0$ and that 
$\frac{\partial \Pi^{*}}{\partial \alpha}=0$ admits at most one solution in $\alpha \in[0, \bar{\alpha}]$ and recalling that $\Pi^{*} \rightarrow 0$ when $\alpha \rightarrow \bar{\alpha}$, it must be the case that $\Pi^{*}$ is monotonically decreasing in $\alpha[0, \bar{\alpha}]$.

\section{A.5 Proof of Proposition 1}

Recall that $L^{*}$ is equal to: (a) $L^{*}=\frac{c^{*}+0}{2 c^{*}}=\frac{1}{2}$ when $\Pi^{*}>c^{*}$; (b) $L^{*}=\frac{c^{*}+c^{*}-\Pi^{*}}{2 c^{*}}=1-\frac{\Pi^{*}}{2 c^{*}}$ when $0<$ $\Pi^{*}<c^{*}$; (c) $L^{*}=\frac{c^{*}+c^{*}}{2 c^{*}}=1$ when $\Pi^{*}=0$. The derivative $\frac{\partial L^{*}}{\partial \alpha}$ is 0 in (a) and (c); we hence focus on (b), where:

$\frac{\partial L^{*}}{\partial \alpha}=\frac{\Pi^{*} \frac{\partial c^{*}}{\partial \alpha}-\frac{\partial \Pi^{*}}{\partial \alpha} c^{*}}{2\left(c^{*}\right)^{2}}$.

The sign of Eq. 17 is equivalent to that of:

$\frac{\partial c^{*}}{\partial \alpha} \frac{\alpha}{c^{*}}-\frac{\partial \Pi^{*}}{\partial \alpha} \frac{\alpha}{\Pi^{*}}$,

where the first term denotes the equilibrium elasticity of $c^{*}$ to $\alpha$ and the second one the equilibrium elasticity of $\Pi^{*}$ to $\alpha$.

To investigate the sign of Eq. 18 in the interval $[0, \bar{\alpha})$, we separately consider three cases: $c_{q \alpha}=0$, $c_{q \alpha}<0$, and $c_{q \alpha}>0$.

\section{A.5.1 $c_{q \alpha}=0$}

When $c_{q \alpha}=0$, Lemmas 1 and 2 ensure that both $p^{*}$ and $\Pi^{*}$ are decreasing in $\alpha$. As a result, the optimal $\operatorname{costs} c^{*}>0$ increases with $\alpha$. Indeed:

$\frac{\partial c^{*}}{\partial \alpha}=c_{\alpha}+c_{q} \frac{\partial q\left(p^{*}\right)}{\partial p^{*}} \frac{\partial p^{*}}{\partial \alpha}$,

where $c_{q \alpha}=0$ implies $c_{\alpha}=0$ and $\frac{\partial p^{*}}{\partial \alpha}<0$ implies $c_{q} \frac{\partial q\left(p^{*}\right)}{\partial p^{*}} \frac{\partial p^{*}}{\partial \alpha}>0$. Since $\Pi^{*}$ is monotonically decreasing in $\alpha \in[0, \bar{\alpha})$ and $\lim _{\alpha \rightarrow \bar{\alpha}} \Pi^{*}=0$, while $c^{*}>0$ is monotonically increasing, equality $\Pi^{*}=c^{*}$ admits zero or one solution.

First suppose equality $\Pi^{*}=c^{*}$ admits no solution; in this case, it must be that $\Pi^{*}<c^{*}$ in $[0, \bar{\alpha})$, hence:

$L^{*}=1-\frac{\Pi^{*}}{2 c^{*}} \in\left(\frac{1}{2}, 1\right)$ when $\alpha \in[0, \bar{\alpha})$,

with $\frac{\partial L^{*}}{\partial \alpha}>0$ because Eq. 18 is positive for any $\alpha \in$ $[0, \bar{\alpha})$.

Suppose now equality $\Pi^{*}=c^{*}$ admits one solution, denoted by $\alpha_{1}$. In this case, it must be that $\Pi^{*} \geq$ $c^{*}$ in $\left[0, \alpha_{1}\right]$ and $\Pi^{*}<c^{*}$ in $\left[\alpha_{1}, \bar{\alpha}\right]$. Summing up:

$L^{*}= \begin{cases}\frac{1}{2} & \text { when } \alpha \in\left[0, \alpha_{1}\right), \\ 1-\frac{\Pi^{*}}{2 c^{*}} \in\left(\frac{1}{2}, 1\right) & \text { when } \alpha \in\left[\alpha_{1}, \bar{\alpha}\right), \text { with } \frac{\partial L^{*}}{\partial \alpha}>0 .\end{cases}$

Overall, $L^{*}$ is (weakly) increasing in $\alpha$ when $c_{q \alpha}=0$.

A.5.2 $c_{q \alpha}<0$

When $c_{q \alpha}<0$, Lemmas 1 ensures that $p^{*}$ is decreasing in $\alpha \in[0, \bar{\alpha})$ and 2 that $\Pi^{*}$ is first increasing and then decreasing in $\alpha \in[0, \bar{\alpha})$. As a result, the sign of Eq. 19 and that of Eq. 18 are ambiguous. Indeed, $c_{q \alpha}<0$ implies $c_{\alpha}<0$, whereas $\frac{\partial p^{*}}{\partial \alpha}<0$ implies $c_{q} \frac{\partial q\left(p^{*}\right)}{\partial p^{*}} \frac{\partial p^{*}}{\partial \alpha}>0$. Assuming that $\frac{\partial c^{*}}{\partial \alpha}=0$ admits at most one solution in $\alpha \in[0, \bar{\alpha})$, the following alternative situations might occur: the impact of $\alpha \in[0, \bar{\alpha})$ on $c^{*}$ can be monotonic (either positive or negative), or nonmonotonic (either U-shaped or inverted U-shaped). Given these alternative relationships between $\alpha$ and $c^{*}$, equality $\Pi^{*}=c^{*}$ admits either zero, or one, or two solutions.

First suppose equality $\Pi^{*}=c^{*}$ admits no solution; in this case, it must be that $\Pi^{*}<c^{*}$ in $[0, \bar{\alpha})$, hence:

$L^{*}=\left\{1-\frac{\Pi^{*}}{2 c^{*}} \in\left(\frac{1}{2}, 1\right)\right.$ when $\alpha \in[0, \bar{\alpha})$, with $\begin{array}{l}\frac{\partial L^{*}}{\partial \alpha}>0 \text { or } \\ \frac{\partial L^{*}}{\partial \alpha} \text { first }<0, \text { then }>0 .\end{array}$

To prove that $\frac{\partial L^{*}}{\partial \alpha}$ is either positive or first negative and then positive in $\alpha \in[0, \bar{\alpha})$, it is sufficient to recall that $\frac{\partial L^{*}}{\partial \alpha}>0$ when $\alpha \rightarrow \bar{\alpha}$ because the first term of Eq. 18 is finite, while the second one tends to infinity.

Suppose now equality $\Pi^{*}=c^{*}$ admits one solution, denoted by $\alpha_{1}$. When $\alpha \rightarrow \bar{\alpha}, \Pi^{*}$ tends to zero, being therefore lower than $c^{*}$. It follows that $\Pi^{*} \geq c^{*}$ in $\left[0, \alpha_{1}\right]$, in which case $L^{*}=\frac{1}{2}$, and $\Pi^{*}<c^{*}$ in $\left[\alpha_{1}, \bar{\alpha}\right]$, in which case $L^{*}=1-\frac{\Pi^{*}}{2 c^{*}}$ with $\frac{\partial L^{*}}{\partial \alpha}>0$. To show that $L^{*}=1-\frac{\Pi^{*}}{2 c^{*}}$ is increasing in $\alpha \in\left[\alpha_{1}, \bar{\alpha}\right]$, we proceed as follows. Since $\Pi^{*} \geq c^{*}$ at $\alpha<\alpha_{1}$ and $\Pi^{*}<c^{*}$ at $\alpha>\alpha_{1}$, it must be the case that $\frac{\partial c^{*}}{\partial \alpha_{1}}>\frac{\partial \Pi^{*}}{\partial \alpha_{1}}$. As a result, Eq. $18>0$ in a neighborhood 
of $\alpha_{1}$. At the same time Eq. 18>0 when $\alpha \rightarrow \bar{\alpha}$. Excluding that Eq. 18 becomes negative at some value of $\alpha$ within $\left(\alpha_{1}, \bar{\alpha}\right)$, we conclude that $\frac{\partial L^{*}}{\partial \alpha}>0$ in $\alpha \in\left[\alpha_{1}, \bar{\alpha}\right]$. Note that for Eq. 18 to become negative at some value of $\alpha$ within $\left(\alpha_{1}, \bar{\alpha}\right), \frac{\partial c^{*}}{\partial \alpha} \frac{\alpha}{c^{*}}$ must be particularly high because the second term of Eq. 18 tends to infinity when $\alpha \rightarrow \bar{\alpha}$. In addition, this peculiar scenario would imply that $L^{*}$ displays both a local maximum and then a local minimum in $\left[\alpha_{1}, \bar{\alpha}\right)$.

Finally, suppose equality $\Pi^{*}=c^{*}$ admits two solutions, denoted by $\alpha_{0}$ and $\alpha_{1}$. Since $\Pi^{*}<c$ when $\alpha \rightarrow \bar{\alpha}$, it must be the case that $\Pi^{*}<c^{*}$ in $\left[0, \alpha_{0}\right)$ and in $\left[\alpha_{1}, \bar{\alpha}\right)$ and $\Pi^{*}>c^{*}$ in $\left[\alpha_{0}, \alpha_{1}\right)$. We claim that:

$L^{*}= \begin{cases}1-\frac{\Pi^{*}}{2 c^{*}} \in\left(\frac{1}{2}, 1\right) & \text { when } \alpha \in\left[0, \alpha_{0}\right), \text { with } \frac{\partial L^{*}}{\partial \alpha}<0 \\ \frac{1}{2} & \text { when } \alpha \in\left[\alpha_{0}, \alpha_{1}\right), \\ 1-\frac{\Pi^{*}}{2 c^{*}} \in\left(\frac{1}{2}, 1\right) & \text { when } \alpha \in\left[\alpha_{1}, \bar{\alpha}\right), \text { with } \frac{\partial L^{*}}{\partial \alpha}>0 .\end{cases}$

To show that $\frac{\partial L^{*}}{\partial \alpha}<0$ in a left neighborhood of $\alpha_{0}$, it is sufficient to observe that $\Pi^{*}<c^{*}$ when $\alpha<\alpha_{0}$ and $\Pi^{*}>c^{*}$ when $\alpha>\alpha_{0}$ imply that $\frac{\partial c^{*}}{\partial \alpha_{1}}<\frac{\partial \Pi^{*}}{\partial \alpha_{1}}$. We exclude that Eq. 18 becomes positive at some intermediate values of $\alpha$ within $\left(0, \alpha_{0}\right)$. Indeed, for this to be true, $\frac{\partial c^{*}}{\partial \alpha}$ must become sufficiently larger than $\frac{\partial \Pi^{*}}{\partial \alpha}$ given that $\frac{\alpha}{c^{*}}<\frac{\alpha}{\Pi^{*}}$ for any given $\alpha<\alpha_{0}$. In addition, this peculiar scenario would imply that $L^{*}$ displays a local maximum in $\left[0, \alpha_{0}\right)$. To show that $\frac{\partial L^{*}}{\partial \alpha}>0$ when $\alpha \in\left[\alpha_{1}, \bar{\alpha}\right)$, we rely on the above reasoning.

Overall, $L^{*}$ is either (weakly) increasing in $\alpha$ or first decreasing and then (weakly) increasing when $c_{q \alpha}<0$.

\section{A.5.3 $c_{q \alpha}>0$}

When $c_{q \alpha}>0$, Lemma 2 ensures that $\Pi^{*}$ is monotonically decreasing in $\alpha \in[0, \bar{\alpha})$, while the impact of $\alpha \in$ $[0, \bar{\alpha})$ on $p^{*}$ is ambiguous according to Lemma 1 . As a result, the sign of Eq. 19 and that of Eq. 18 are ambiguous.

More precisely, when $\frac{\partial p^{*}}{\partial \alpha}<0$ for any $\alpha \in[0, \bar{\alpha})$, then $c^{*}$ is monotonically increasing in $\alpha \in[0, \bar{\alpha})$ because $c_{q \alpha}>0$ implies $c_{\alpha}>0$ and $\frac{\partial p^{*}}{\partial \alpha}<0$ implies $c_{q} \frac{\partial q\left(p^{*}\right)}{\partial p^{*}} \frac{\partial p^{*}}{\partial \alpha}>0$; in this case, the relationship between $\alpha$ and $L^{*}$ is as in Appendix A.5.1.

When, instead, the impact of $\alpha \in[0, \bar{\alpha})$ on $p^{*}$ is positive or nonmonotonic, the relationship between $c^{*}$ and $\alpha$ can be monotonic (either positive or negative), or nonmonotonic (either U-shaped or inverted U-shaped). In this scenario, equality $\Pi^{*}=c^{*}$ admits either zero, or one, or two solutions and the relationship between $\alpha$ and, in the cases where $c^{*}$ decreases in $\alpha$, the relationship between $\alpha$ and $L^{*}$ is as in Appendix A.5.2.

Overall, when $c_{q \alpha} \neq 0, L^{*}$ is either (weakly) increasing in $\alpha$ or first decreasing and then (weakly) increasing when $c_{q \alpha}<0$.

\section{Appendix B: Empirical analysis: robustness checks}

\section{B.1 Dynamics and endogeneity}

In this section, we investigate if our results hold when concerns about the dynamics of the process and endogeneity of the financial variables $X_{i p t}$ are taken into consideration. We enrich the specification of our static model (8) by considering the leverage of the previous year:

$$
\begin{aligned}
\log L_{i p t}= & \rho \log L_{i p t-1}+X_{i p t}^{\prime} \beta_{\tau}+P_{p t}^{\prime} \gamma \\
& +Z_{t}^{\prime} \pi+V_{p} \delta+v_{i p}+e_{i p t},
\end{aligned}
$$

We estimate Eq. 23 using a one-step GMM estimator in the manner of Arellano and Bover (1995). The estimator combines orthogonality conditions for the equation in levels and in first difference. We use the orthogonality conditions in levels to identify $\delta$, the parameters of our time-invariant proxy for the client orientation of the SCs. These orthogonality conditions are defined with respect to the variables in $P_{p t}, Z_{t}$, and $V_{p}$ for which exogeneity is granted. We use instead $\log L_{i p t-2}, \log L_{i p t-3}, X_{i p t-2}$, and $X_{i p t-3}$ as instruments in the orthogonality conditions for the equation in first difference. The choice of these instruments is likely to secure a good correlation between endogenous and instrumental variables. The use of lagged variables makes the number of observations to drop from 38,758 to 30,912 , the covered period is limited to 2006-2013, and the share of start-up SCs drops from 24 to $17.8 \%$. Given the relevant change of the estimation sample, Table 3 shows both the GMM and the OLS estimates on this restricted sample.

Inspection and testing on the parameters of the first stage equations confirm that the instruments are appropriate in that they are correlated with the endogenous 
variables; the Hansen J over-identification test and the Arellano-Bond test for AR(2) in first differences error do not reject the hypothesis of correct specification.

The OLS estimates on the restricted sample (column (2), Table 3) confirm the results for the entire sample (Table 2). In particular, the estimate of the parameter related to our main variable of interest, that is, the voluntary workers/total workforce ratio, is fully coherent with the results in Table 2. The other parameters show little differences with respect to the full sample case. When we consider the dynamic model-column (1), Table 3-the point estimate of the autoregressive coefficient is 0.398 , statistically different from zero: coops with past high leverage tend to persist in their level of indebtedness. The estimated impact of some financial indicators on leverage changes remarkably. The value of the assets gains relevance, whereas the incidence of the operating grants
Table 3 GMM estimates of Eq. 23 and OLS estimates for Eq. 8 on the same sample. Specification includes also time $\left(Z_{t}\right)$ dummies. Standard errors robust to heteroskedasticity and clustering at provincial level (103 clusters).

Number of obs $=30,912$.

OLS estimates: $R^{2}=0.09$; GMM estimates: Hansen J statistics: $9.35, \chi_{6} p$ value: 0.15 ; Arellano-Bond test for $\mathrm{AR}(2)$ in first differences: 1.87. $R^{2}=0.55$ (squared correlation between observed and predicted value)

Robust standard errors in parentheses

$* * * p<0.01, * * p<0.05, * p<$ 0.1

\begin{tabular}{|c|c|c|}
\hline & (1) & (2) \\
\hline Variables & GMM estimates (23) & $\begin{array}{l}\text { OLS estimates (8) } \\
\text { restricted sample }\end{array}$ \\
\hline Voluntary workers/total workforce & $\begin{array}{l}-0.357 * * \\
(0.159)\end{array}$ & $\begin{array}{l}-0.414 * * \\
(0.171)\end{array}$ \\
\hline $\log$ Leverage $_{i p t-1}$ & $\begin{array}{l}0.398 * * * \\
(0.0387)\end{array}$ & \\
\hline $\log$ (total assets) & $\begin{array}{l}0.0846 * * \\
(0.0426)\end{array}$ & $\begin{array}{l}0.000687 \\
(0.00714)\end{array}$ \\
\hline Tangible assets/total assets & $\begin{array}{l}0.108 \\
(0.164)\end{array}$ & $\begin{array}{l}-0.0126 \\
(0.0500)\end{array}$ \\
\hline ROA & $\begin{array}{l}-0.269^{*} \\
(0.147)\end{array}$ & $\begin{array}{l}-0.718 * * * \\
(0.0287)\end{array}$ \\
\hline Labor cost/total production value & $\begin{array}{l}0.297 * * * \\
(0.106)\end{array}$ & $\begin{array}{l}-0.315 * * * \\
(0.0431)\end{array}$ \\
\hline Operating grants/total production value & $\begin{array}{l}0.367 \\
(0.346)\end{array}$ & $\begin{array}{l}-0.311 * * * \\
(0.110)\end{array}$ \\
\hline Residential services & $\begin{array}{l}-0.0807 * * * \\
(0.0286)\end{array}$ & $\begin{array}{l}-0.0797 * * * \\
(0.0213)\end{array}$ \\
\hline Start up & $\begin{array}{l}0.295 * * * \\
(0.0603)\end{array}$ & $\begin{array}{l}0.271 * * * \\
(0.0182)\end{array}$ \\
\hline New nonperforming loans/performing loans & $\begin{array}{l}0.0105 * * \\
(0.00434)\end{array}$ & $\begin{array}{l}0.00936^{*} \\
(0.00550)\end{array}$ \\
\hline Net flow of new companies/active companies & $\begin{array}{l}0.00672 * \\
(0.00348)\end{array}$ & $\begin{array}{l}0.00940 * \\
(0.00475)\end{array}$ \\
\hline Population over 55/total population & $\begin{array}{l}0.799 * * \\
(0.386)\end{array}$ & $\begin{array}{l}1.455^{* * * *} \\
(0.492)\end{array}$ \\
\hline $\log$ (population) & $\begin{array}{l}0.0335 * \\
(0.0195)\end{array}$ & $\begin{array}{l}0.0511 * * \\
(0.0200)\end{array}$ \\
\hline Added value per capita & $\begin{array}{l}1.861 \\
(2.421)\end{array}$ & $\begin{array}{l}-0.178 \\
(2.451)\end{array}$ \\
\hline Employment rate & $\begin{array}{l}-0.00794 * * * \\
(0.00263)\end{array}$ & $\begin{array}{l}-0.00570 * * * \\
(0.00205)\end{array}$ \\
\hline Constant & $\begin{array}{l}-1.422 * * * \\
(0.302)\end{array}$ & $\begin{array}{l}-1.291 * * * \\
(0.342)\end{array}$ \\
\hline
\end{tabular}


on the value of production becomes less relevant. More importantly, the new estimated value of our main parameter of interest is -0.357 ; this value is in line with the OLS estimates for the static model (8) for the full-Table 2-and the restricted sample—column (1), Table 3

\section{B.2 Unobserved heterogeneity}

To assess to what extent our results are robust to the presence of unobserved omitted factors, we apply the methodology recently suggested by Oster (2019). Following her notation, we define $\omega_{i p t}^{o}=$ $\left(X_{i p t}^{\prime}, P_{p t}^{\prime}, Z_{t}\right)^{\prime}$ the set of observed control variables, $V_{p}$ the treatment of interest, and assume that $\log L_{i p t}$ is also determined by an unobservable index $W_{2 i p t}$, orthogonal to the components of $\omega_{i p t}^{o}$, and the regression error, $u_{i p t}=v_{i p}+e_{i t}$ :

$\log L_{i p t}=V_{p} \delta+\omega_{i p t}^{o \prime} \Psi+W_{2 i p t}+u_{i p t}$.

We define the index $W_{1 i p t}=\omega_{i p t}^{o \prime} \Psi$ and the coefficient of proportionality $\eta=\left(\sigma_{2 V} / \sigma_{2}^{2}\right) /\left(\sigma_{1 V} / \sigma_{1}^{2}\right)$ where $\sigma_{k V}=\operatorname{Cov}\left(W_{k i p t}, V_{p}\right)$ and $\sigma_{k}^{2}=\operatorname{Var}\left(W_{k i p t}\right)$ for $k=1,2$. We denote with $R_{\max }^{2}$ the $R^{2}$ of the hypothetical regression (24) of the dependent variable on the observable and unobservable factors. Oster's approach to robustness is to assume a value for $R_{\max }^{2}$ and calculate the value of $\eta$ for which the parameter of interest $\delta$ is zero. This value can be interpreted as "the degree of selection on unobservables relative to observables that would be necessary to explain away the result (under the full model hypothesized)" (Oster, 2019 , p. 195). For example, a value of $\eta=2$ "would suggest that the unobservables would need to be twice as important as the observables to produce a treatment effect of zero." (Oster, 2019, p. 195) An approach to assess the role played by the unobservables is to report the value of $R_{\max }^{2}$ for which $\delta=0$ if $\eta=1$. "This value could then be discussed in terms of whether it is plausible that the unobservables explain more of the variance than implied by this value." Using the Oster's Stata code (https://ideas.repec.org/c/boc/ bocode/s457677.html), in Fig. 4, we plot the value of $\eta$ for which $\delta=0$ in our estimates of Eq. 8 as a function of the hypothetical $R_{\max }^{2}$. The the coefficient of proportionality $\eta$, that is the degree of selection on the unobservables relative to observables necessary to explain away the effect of $V_{p}$ (our proxy for $\alpha$ ), decreases with $R_{\max }^{2}$. In particular, $\eta$ falls below the threshold of 1 -suggested as benchmark by Altonji et al. (2005) and Oster (2019)—only when $R_{\max }^{2}$ is higher than 0.3 , that is, three times as big as our actual $R^{2}$. We read this as evidence that our results can be considered robust, unless unobserved components are preponderant over the observable ones.

\section{B.3 Residential and nonresidential services}

We re-estimate Eq. 8 with OLS by splitting the sample into residential and nonresidential SCs. The results are shown in Table 4. Excluding the asset
Fig. 4 Degree of selection on unobservables relative observables that would be necessary to explain away to effect of $\alpha$

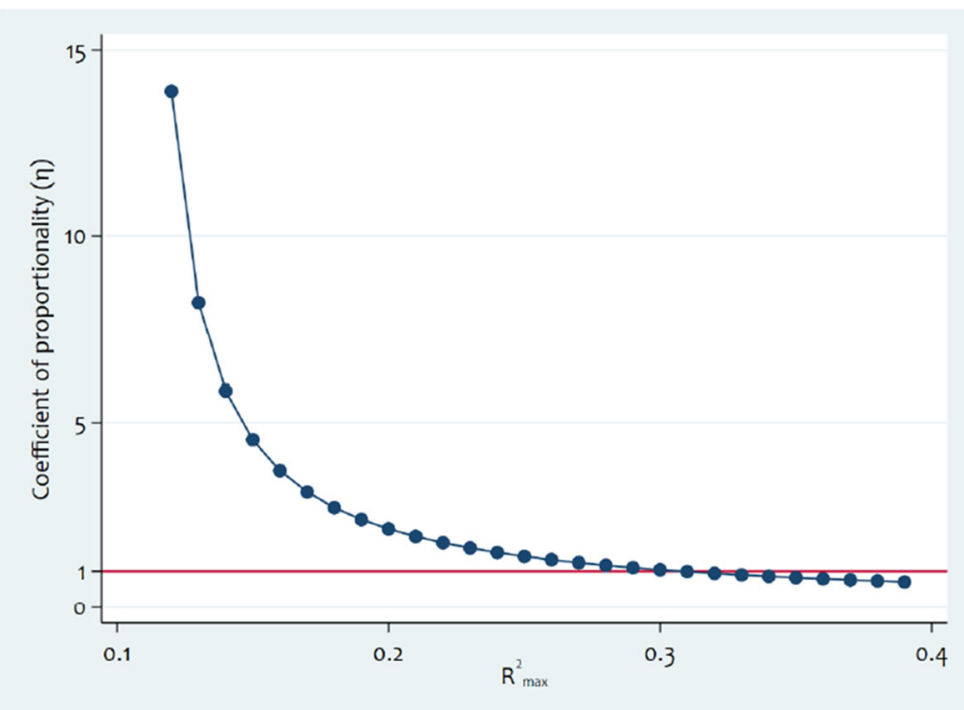


tangibility indicator, which brings a negative and statistically significant parameter only for the residential sector, the differences across sectors in the estimated parameters are negligible. As for the proxy for client orientation, a one percentage point increase in the voluntary workers/total workforce ratio is associated with a $0.62 \%$ drop in the leverage of residential SCs and a $0.39 \%$ drop for SCs providing nonresidential services. These figures confirm our main finding that stronger client orientation is associated with lower leverage.
Table 4 OLS estimates of Eq. 8 by sector.

Specification includes also time $\left(Z_{t}\right)$ dummies.

Standard errors robust to heteroskedasticity and clustering at provincial level (103 clusters)
Robust standard errors in parentheses

$* * * p<0.01, * * p<0.05, * p<0.1$

(1)

(2)

Variables

Voluntary workers/total workforce

$\log$ (total assets)

Tangible assets/total assets

ROA

Labor cost/total production value

Operating grants/total production value

Start up

New nonperforming loans/performing loans

Net flow of new companies/active companies

Population over 55/total population

$\log$ (population)

Added value per capita

Employment rate

Constant

Observations

$R$-squared
Residential services Non-residential services

$\begin{array}{ll}-0.616^{* *} & -0.385^{* *} \\ (0.296) & (0.158) \\ 0.00436 & -0.000290 \\ (0.0145) & (0.00733) \\ -0.205^{*} & 0.0780 \\ (0.108) & (0.0473)\end{array}$

$-0.805 * * * \quad-0.704 * * *$

(0.0603)

(0.0250)

$-0.211 * * \quad-0.268 * * *$

(0.0841) (0.0355)

$-0.293-0.323 * * *$

(0.264) (0.0953)

$0.337 * * * \quad 0.269 * * *$

(0.0348) (0.0192)

0.00781

$(0.00583)$

$0.0104 * *$

(0.00505)

$1.334 * * *$

(0.494)

$0.0467 * *$

(0.0195)

$-1.072$

(2.352)

$-0.00398 *$

(0.00206)

$-1.302 * * *$

(0.325)

30,865

0.104 


\section{References}

Akinleye, D., McNutt, L., Lazariu, V., McLaughlin, C. (2019). Correlation between hospital finances and quality and safety of patient care. Plos One. https://doi.org/10.1371/journal.pone.0219124.

Altonji, J.G., Elder, T.E., Taber, C.R. (2005). An evaluation of instrumental variable strategies for estimating the effects of catholic schooling. Journal of Human Resources, 40, 791821.

Arellano, M., \& Bover, O. (1995). Another look at the instrumental variable estimation of error-components models. Journal of Econometrics, 68(1), 29-51.

Bacon, P.W. (1992). Do capital structure theories apply to nonprofit hospitals. Journal of the Midwest Finance Association, 21(1), 86-90.

Bae, K.H., Kang, J.K., Wang, J. (2011). Employee treatment and firm leverage: a test of the stakeholder theory of capital structure. Journal of Financial Economics, 100(1), 130-153.

Baker, M., \& Wurgler, J. (2002). Market timing and capital structure. Journal of Finance, 57(1), 1-32.

Banerjee, S., Dasgupta, S., Kim, Y. (2008). Buyer-Supplier Relationships and the stakeholder theory of capital structure. The Journal of Finance, 63(5), 2507-2552.

Borzaga, C., Depedri, S., Tortia, E.C. (2011). Testing the distributive effects of social enterprises: the case of italy. In Sacconi, L., \& Degli Antoni, G. (Eds.) Social capital, corporate social responsibility, economic behaviour and performance (pp. 282-303). New York: Palgrave.

Borzaga, C., \& Fazzi, L. (2014). Civil society, third sector, and healthcare: the case of social cooperatives in Italy. Social Science and Medicine, 123, 234-241.

Bowman, W. (2002). The uniqueness of nonprofit finance and the decision to borrow. Nonprofit Management \& Leadership, 12(3), 293-311.

Brekke, K., Siciliani, L., Straume, O.R. (2012). Quality competition with profit constraints. Journal of Economic Behavior \& Organization, 84(2), 642-659.

Calabrese, T.D. (2011). Testing competing capital structure theories of nonprofit organizations. Public Budgeting and Finance, 31(3), 119-143.

Calò, F., Teasdale, S., Donaldson, C., Roy, M., Baglioni, S. (2018). Collaborator or competitor: assessing the evidence supporting the role of social enterprise in health and social care. Public Management Review, 20(12), 1790 1814. https://doi.org/10.1080/14719037.2017.1417467.

Devereux, M., Maffini, G., Xing, J. (2019). The impact of investment incentives: evidence from UK corporation tax returns. American Economic Journal: Economic Policy, 11(3), 361-89.

de Jong, A., Verbeek, M., Verwijmeren, P. (2011). Firms' debt-equity decisions when the static tradeoff theory and the pecking order theory disagree. Journal of Banking \& Finance, 35, 1303-1314.

Dong, G. (2015). Performing well in financial management and quality of care: evidence from hospital process measures for treatment of cardiovascular disease. BMC Health Services Research, 15(45). https://doi.org/10.1186/s12913-015-0690-x.

Encinosa, W., \& Bernard, D. (2005). Hospital finances and patient safety outcomes. Inquiry, 42(1), 60-72. https://doi.org/10.5034/inquiryjrnl_42.1.60.

El Ghoul, S., Guedhami, O., Kwok, C.C.Y., Mishra, D.R. (2011). Does corporate social responsibility affect the cost of capital?. Journal of Banking \& Finance, 35, 2388-2406.

Fedele, A., \& Miniaci, R. (2010). Do social enterprises finance their investments differently from for-profit firms? the case of social residential services in Italy. Journal of Social Entrepreneurship, 1(2), 174-189.

Fedele, A., \& Depedri, S. (2016). In Medio Stat Virtus: does a mixed economy increase welfare? Annals of Public and Cooperative Economics, 87(3), 345-363.

Galera, G., \& Borzaga, C. (2009). Social enterprise: an international overview of its conceptual evolution and legal implementation. Social Enterprise Journal, 5(3), 210-228.

Goss, A., \& Roberts, G.S. (2011). The impact of corporate social responsibility on the cost of bank loans. Journal of Banking \& Finance, 35, 1794-1810.

Halling, M., Yu, J., Zechner, J. (2016). Leverage dynamics over the business cycle. Journal of Financial Economics, 122, 21-41.

Hansmann, H.B. (1980). The role of nonprofit enterprise. Yale Law Journal, 89, 835-898.

Hansmann, H. (1996). The ownership of the enterprise Harvard. Cambridge: Harvard University Press.

Hediger, W. (2010). Welfare and capital-theoretic foundations of corporate social responsibility and corporate sustainability. The Journal of Socio-Economics, 39(4), 518-526.

Herr, A. (2011). Quality and welfare in a mixed duopoly with regulated prices: the case of a public and a private hospital. German Economic Review, 12(4), 422-437.

Hiller, J.S. (2013). The benefit corporation and corporate social responsibility. Journal of Business Ethics, 118(2), 287-301.

Huang, S.S., Yang, J., Carroll, N. (2018). Taxes, bankruptcy costs, and capital structure in for-profit and not-for-profit hospitals. Health Services Management Research, 31(1), 21-32.

Kale, J.R., \& Shahrur, H. (2007). Corporate capital structure and the characteristics of suppliers and customers. Journal of Financial Economics, 83(2), 321-365.

Kitzmüller, M., \& Shimshack, J. (2012). Economic perspectives on corporate social responsibility. Journal of Economic Literature, 50(1), 51-84.

Lioui, A., \& Sharma, Z. (2012). Environmental corporate social responsibility and financial performance: disentangling direct and indirect effects. Ecological Economics, 78, $100-111$

Marino, D., \& Schenkel, M. (2017). Recent trends in volunteerism: a comparison between european and North/South american countries. In Gil-Lafuente, J., Marino, D., Morabito, F.C. (Eds.) Economy, business and uncertainty: New ideas for a euro-mediterranean industrial policy (pp. 5883). Heidelberg: Springer.

Michelutti, M., \& Schenkel, M. (2009). Working for nothing and being happy. The determinants of the satisfaction of volunteers and paid workers. In Destefanis, S., \& Musella, M. (Eds.) Paid and unpaid labour in the social economy: An international perspective. 81-96: Springer. 
Myers, S., \& Majluf, N. (1984). Corporate financing and investment decisions when firms have information that investors do not have. Journal of Financial Economics., 13(2), 187221

Opler, T., \& Titman, S. (1993). The determinants of leveraged buyout activity: free cash flow vs. financial distress costs. The Journal of Finance, 48(5), 1985-1999.

Opler, T., \& Titman, S. (1994). Financial distress and corporate performance. The Journal of Finance, Papers and Proceedings, 49(3), 1015-1040.

Oster, E. (2019). Unobservable selection and coefficient stability: theory and evidence. Journal of Business \& Economic Statistics, 37(2), 187-204.

Parsons, C., \& Titman, S. (2008). Empirical capital structure: a review. Foundations and Trends in Finance, 3(1), 1-93.

Poledrini, S., \& Tortia, E.C. (2020). Social Enterprises: Evolution of the Organizational Model and Application to the Italian Case. Entrepreneurship Research Journal, 10(4), 20190315. https://doi.org/10.1515/erj-2019-0315.

Sacchetti, S., \& Borzaga, C. (2020). The foundations of the "public organization": governance failure and the problem of external effects. Journal of Management and Governance. Online first. DOI:. https://doi.org/10.1007/ s10997-020-09525-x.

Siqueira, A.C.O., Guensterb, N., Vanackerc, T., Cruckec, S. (2018). A longitudinal comparison of capital structure between young for-profit social and commercial enterprises. Journal of Business Venturing, 33, 225-240.

Szymanska, A., \& Jegers, M. (2016). Modelling social enterprises. Annals of Public and Cooperative Economics, 87(4), 501-527.

Titman, S. (1984). The effect of capital structure on a firm's liquidation decision. Journal of Financial Economics, 13(1), 137-151.

Trussel, J. (2012). A comparison of the capital structures of nonprofit and proprietary health care organizations. Journal of Health Care Finance, 39(1), 1-11.
Turner, J.S., Broom, K., Elliot, M., Lee, J.F. (2015). A comparison of capital structure: the use of debt in investor owned and Not-For-Profit hospitals. Journal of Health Care Finance, 41(4), 1-16.

Verwijmeren, P., \& Derwall, J. (2010). Employee well-being, firm leverage, and bankruptcy risk. Journal of Banking \& Finance, 34, 956-964.

Vidal, I. (2014). Multi-stakeholder governance in social enterprise. In Defourny, J., Hulgård, L., Pestoff, V. (Eds.) Social enterprise and the third sector: changing European landscapes in a comparative perspective (pp. 176-186). London: Routledge.

Wedig, G., Sloan, F.A., Hassan, M., Morrisey, M.A. (1988). Capital structure, ownership, and capital payment policy: The case of hospitals. The Journal of Finance, 43 (1), 21-40.

Wedig, G. (1990). Hospital capital structure and prospective payment: theory and evidence of hospital behavior under financial risk. Journal of the Midwest Finance Association, $19,69-84$.

Wedig, G., Hassan, M., Morrisey, M.A. (1996). Tax-exempt debt and the capital structure of nonprofit organizations: an application to hospitals. The Journal of Finance, 51(4), 1247-1283.

Wheeler, J.R.C., Smith, D., Rivenson, H., Reiter, K. (2000). Capital structure strategy in health care systems. Journal of Health Care Finance, 26(4), 42-63.

Wilson, F., \& Post, J.E. (2013). Business models for people, planet (\& profits): exploring the phenomena of social business, a market-based approach to social value creation. Small Business Economics, 40, 715-737.

Yunus, M. (2007). Creating a world without poverty: social business and the future of capitalism. New York: Public Affairs.

Publisher's note Springer Nature remains neutral with regard to jurisdictional claims in published maps and institutional affiliations. 